\section{L'Actualité économique}

L'ACTUALITÉ ÉCONOMIQUE

--> Voir l'erratum concernant cet article

\section{L’aluminium au Canada}

\section{Benoît Brouillette}

Volume 37, numéro 3, octobre-décembre 1961

URI : https://id.erudit.org/iderudit/1001734ar

DOI : https://doi.org/10.7202/1001734ar

Aller au sommaire du numéro

Éditeur(s)

HEC Montréal

ISSN

0001-771X (imprimé)

1710-3991 (numérique)

Découvrir la revue

Citer cet article

Brouillette, B. (1961). L'aluminium au Canada. L'Actualité économique, 37(3),

424-479. https://doi.org/10.7202/1001734ar d'utilisation que vous pouvez consulter en ligne.

https://apropos.erudit.org/fr/usagers/politique-dutilisation/ 


\section{L'aluminium au Canada}

Depuis une quinzaine d'années, l'industrie canadienne de l'aluminium s'est transformée profondément. En étudiant la région du Saguenay en $1946^{1}$, nous avions tracé brièvement l'histoire de cette industrie et montré le rôle qu'elle avait joué durant le conflit mondial qui venait de se terminer. Son avenir nous était apparu assez sombre. "Les beaux jours sont passés, écrivions-nous, tant pour la production que pour l'embauchages ${ }^{2}$. Les usines d'électrolyse d'Arvida et de l'Isle-Maligne, dont la capacité était de 350,000 tonnes, avaient produit moins de 200,000 tonnes en 1949, et l'embauchage qui avait atteint 9,400 en 1944 n'était plus que de 3,500 en 1946.

Le problème de l'époque était celui de la reconversion ou plus précisément celui de trouver de nouveaux débouchés. Or il fut résolu, car le Canada fabrique maintenant beaucoup plus d'aluminium qu'en 1943, la meilleure année de la guerre (voir le graphique I). Ce serait un sujet différent de celui que nous voulons traiter que d'analyser les causes d'un progrès aussi surprenant. Disons simplement qu'il est attribuable d'abord au fait que l'avionnerie, principale cliente de l'aluminium, s'est grandement développée tant pour des fins militaires que civiles; et que le métal léger trouve désormais de multiples usages, surtout dans la construction, l'industrie électrique, avant même les transports, et dans beau-

1. Benoît Brouillette: «L'aluminium au Saguenay», L'Actualité Économique, $22^{\circ}$ année, no 3 , octobre 1946, pp. $417 \cdot 446$.

2. Ibid., p. 437. 
L'ALUMINIUM AU CANADA

Graphique $\mathrm{I}^{1}$

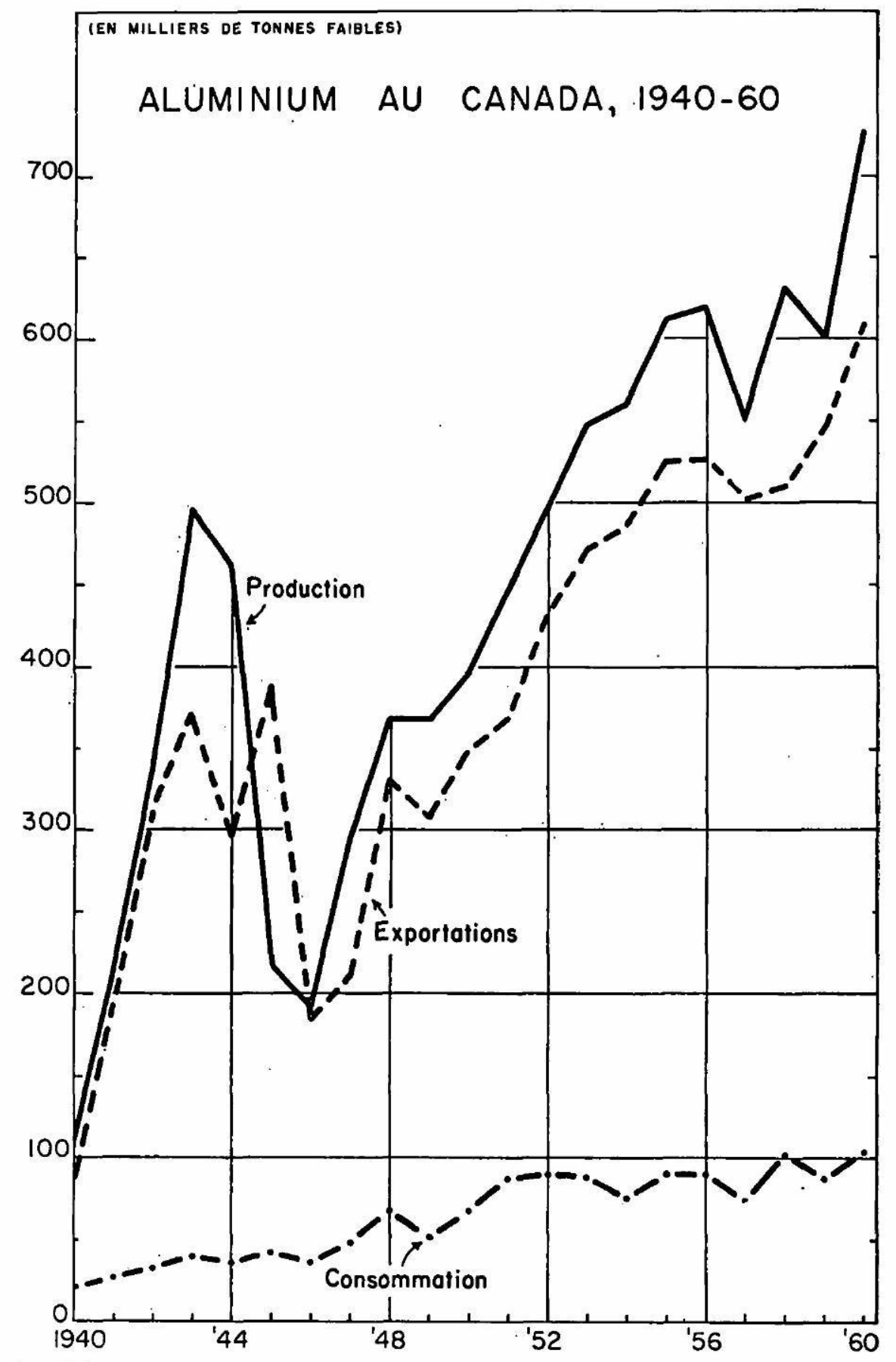

1. Sources: Minerals of Canada (Statistical Supplement), et Aluminum 1959. 
coup d'autres domaines. Voici quels sont les principaux usages de l'aluminium au Canada en 1960':

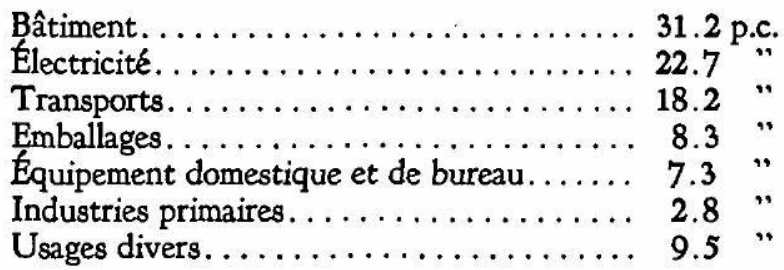

La production canadienne, après de légers reculs en 1957 et 1959, s'est élevée, en 1960, au sommet record de 745,000 tonnes.

Nous nous proposons, dans cet article, d'analyser les courants commerciaux engendrés par l'industrie canadienne de l'aluminium, selon les méthodes que nous avons employées pour d'autres produits. Nous verrons que ces courants sont complexes, qu'ils portent d'abord sur les matières premières, la bauxite et l'alumine, et qu'ils concernent surtout les produits fabriqués, l'aluminium brut et ses dérivés. Le Canada étant un faible consommateur d'aluminium (environ 100,000 tonnes), il dispose donc de forts excédents que nous allons suivre sur les marchés extérieurs, sans lesquels l'industrie canadienne serait fort mal en point. Tel est justement le problème essentiel qu'eurent à résoudre, la guerre terminée, les fabricants canadiens d'aluminium: produire massivement à un prix de concurrence une marchandise destinée à l'exportation. C'est ce qu'ils ont réussi à faire, du moins jusqu'à présent.

Laluminium canadien provient surtout, comme nous l'avions vu en 1946, de la province de Québec; mais celle-ci n'est plus la seule productrice. Et même dans le Québec, l'Alcan est concur. rencée par un producteur nouveau. Il existe désormais six usines d'électrolyse au Canada (voir tableau I) dont la capacité totale est de 871,600 tonnes en 1960. Cependant le Québec demeure, et de loin, le plus gros producteur, avec vraisemblablement les quatre cinquièmes du total. Les principales usines sont les mêmes que celles que nous avions décrites en 1946, sauf une, mais elles ont grossi ${ }^{2}$. Arvida dispose d'une vaste usine de préparation du minerai,

1. Revue de l'Aluminium (Paris), décembre 1960, no 282, p. 1389.

2. Michel.G. Hugueney, «L'industrie canadienne de l'aluminium», Revue de l'Aluminium (Paris), mai 1958, no 254, pp. 511-514; juin 1958, no 255, pp. 629-631. 
la seule au Canada qui traite la bauxite importée pour en faire de l'alumine, d'une usine d'électrolyse qui donne de 250,000 à 300,000 tonnes de lingots, selon le rythme de la production, ainsi que d'autres usines qui fabriquent de 15,000 à 16,000 tonnes d'articles semi-ouvrés et ouvrés. Cette ville reste bien la capitale de l'industrie canadienne de l'aluminium.

\section{Tableau I}

Répartition actuelle des usines d'aluminium au Canada (capacité annuelle en tonnes faibles)

\begin{tabular}{|c|c|c|c|}
\hline PROVINCES & $\begin{array}{l}\text { Traitement } \\
\text { de l'alumine }\end{array}$ & $\begin{array}{c}\text { Usines } \\
\text { d'Electrolyse } \\
\text { (31 dec. 1960) }\end{array}$ & $\begin{array}{l}\text { Autres usines } \\
\text { (sept. 1959) }\end{array}$ \\
\hline \multicolumn{4}{|l|}{ QUÉBEC } \\
\hline $\begin{array}{l}\text { Arvida: } \\
\text { Aluminum Co. of Canada.. }\end{array}$ & $1,250,000$ & 367,000 & 15,960 \\
\hline ISLE-MALIGNE: & & & \\
\hline Aluminum Co. of Canada... & 一 & 115,000 & - \\
\hline $\begin{array}{l}\text { BaIE-ComeAu: } \\
\text { Canadian British Aluminium Co... }\end{array}$ & - & 89,600 & 一 \\
\hline $\begin{array}{l}\text { SHawinigan: } \\
\text { Aluminum Co: of Canada.......... }\end{array}$ & - & 70,000 & 28,000 \\
\hline $\begin{array}{l}\text { BeauHarnots: } \\
\text { Chryslum Ltd. . . . . . . . }\end{array}$ & - & 38,000 & - \\
\hline $\begin{array}{l}\text { CAP-DE-LA-MADBLEINB: } \\
\text { Reynolds Aluminum Co. of Canada }\end{array}$ & - & - & 17,000 \\
\hline Total du 2uébec. & $1,250,000$ & 679,600 & 60,960 \\
\hline \multicolumn{4}{|l|}{ ONTARIO } \\
\hline $\begin{array}{l}\text { Aluminum Co. of Canada... } \\
\text { ETOвicoke (Toronto): }\end{array}$ & - & - & 41,000 \\
\hline Aluminum Co. of Canada. & - & - & 5,700 \\
\hline $\begin{array}{l}\text { Toronto: } \\
\text { Aluminum Goods Ltd.... }\end{array}$ & - & - & 3,000 \\
\hline Total de lOntario...... & $\div$ & - & 49,700 \\
\hline $\begin{array}{l}\text { COLOMBIE-BRITANNIQUE } \\
\text { KIrIMAT: } \\
\text { Aluminum Co. of Canada. }\end{array}$ & - & 192,000 & - \\
\hline $\begin{array}{l}\text { VANCOUVER: } \\
\text { Aluminum Co. of Canada. }\end{array}$ & - & - & 4,800 \\
\hline Total de la Colombie-Britannique. & - & 192,000 & 4,800 \\
\hline Total du Canada. & $1,250,000$ & 871,600 & 115,460 \\
\hline
\end{tabular}


Toutefois, c'est à l'Isle-Maligne que l'Alcan a réalisé ses agrandissements les plus considérables dans le Québec depuis 15 ans. La capacité de l'usine d'électrolyse a décuplé, passant de 18,000 tonnes, en 1945, à 115,000 tonnes aujourd'hui. Pour y parvenir, il fallait de nouvelles sources d'énergie électrique. L'Alcan les a trouvées sur la rivière Péribonka, dont elle avait régularisé le débit au moment où elle construisit Shipshaw. Trois centrales hydroélectriques y furent installées: la Chute-du-Diable, en 1953, où 5 turbines ont une puissance de 275,000 H.P.; la Chute-à-la-Savane, en 1954, avec une puissance de 285,000 H.P., la Chute-des-Passes, de 1959 à 1961, dont la puissance des 5 turbines est d'un million de H.P., soit la plus considérable du Saguenay après Shipshaw. L'Alcan dispose d'un excédent d'énergie. Il peut compter pour sa production d'aluminium sur environ 1,700,000 H.P., et le reste, soit 800,000 H.P., est à la disposition de l'industrie et de la population.

A Shawinigan, où l'Alcoa avait établi la première usine d'aluminium vers 1900, se trouvent deux établissements qui ont grandi: une usine d'électrolyse, ayant désormais une capacité de 70,000 tonnes et une tréflerie de 28,000 tonnes. Enfin l'usine d'électrolyse de Beauharnois est louée à bail à la société Chryslum Ltd, une filiale conjointe de l'Alcan et de Chrysler Corporation of Canada, et peut produire 38,000 tonnes d'aluminium en lingots utilisés comme alliage dans l'industrie de l'automobile. L'usine que l'Alcan avait installée à La Tuque, sur la Saint-Maurice, durant la guerre, a été abandonnée. Bref, dans notre Province, l'Alcan demeure au premier rang avec une capacité de production de 590,000 tonnes d'aluminium brut. Son concurrent, le seul qu'elle ait au Canada, s'est installé à Baie-Comeau, sur la rive nord de l'estuaire du Saint-Laurent entre 1955 et 1957. C'est la société Canadian British Aluminum, qui n'a guère de britannique que le nom, car elle est contrôlée par Reynolds Metals, le rival qui eut raison de l'Alcoa aux Etats-Unis lors de luttes épiques durant les vingt dernières années. Il est vrai cependant que Tube Investments d'Angleterre participe aussi à la gestion de l'entreprise. Les investissements faits à Baie-Comeau furent d'environ 50 millions de livres sterling et partagés entre British Aluminum (60 p.c.) et Quebec North Shore Paper Co. (40 p.c.). Baie-Comeau, dotée déjà d'une vaste usine de 


\section{L'ALUMINIUM AU CANADA}

pâte et papier, est un centre bien choisi pour l'aluminium, mieux peut-être qu'Arvida, car aucun transbordement de matières premières ni de produits finis n'est requis entre le port de mer et l'usine. On souhaite même en faire un port ouvert toute l'année, chose peu probable mais non impossible. L'énergie électrique existe en abondance à proximité. La nouvelle entreprise s'est assurée d'une participation de 40 p.c. dans la centrale hydro-électrique établie par la Quebec North Shore Paper sur la Manicouagan de 1952 à 1957, et elle achète ce qui lui manque de l'Hydro-Québec, aux centrales de Bersimis dont la puissance totale s'élève à deux millions de H.P. L'usine d'électrolyse a une capacité voisine de 90,000 tonnes destinée à être doublée dès que le besoin se fera sentir. On vient d'annoncer, en effet, que le troisième stade d'expansion va se réaliser ${ }^{1}$. La capacité de l'usine sera augmentée de moitié pour atteindre 125,000 tonnes. Les travaux débuteront en 1963 et seront terminés en 1965. Les dépenses prévues sont d'environ 36 millions de dollars. Le nombre de travailleurs qui fut d'environ 600 au début se gonflera à plus de 1,000. Des accords sont intervenus avec l'Hydro-Québec qui fournira le supplément nécessaire d'énergie. L'usine de Baie-Comeau fut ravitaillée en alumine jusqu'en 1961 par Arvida, ainsi que nous l'indiqueront les courants commerciaux. L'Alcan recevait de l'aluminium brut en échange, selon une méthode de troc qu'elle pratique aussi avec la Norvège. Mais il semble qu'à l'avenir, Baie-Comeau recevra ses fournitures en matières premières des Etats-Unis, de la Société Reynolds à laquelle elle est affiliée.

Le même groupe financier contrôle d'autres usines d'aluminium qui transforment ce métal au Canada: une fabrique de tôles et de matériel d'emballage au Cap-de-la-Madeleine, près de TroisRivières, ayant une capacité de 17,000 tonnes, une usine à Toronto qui fabrique d'autres sortes d'emballage, et une tréfilerie projetée à Brockville, en Ontario.

Hors du Québec, l'Alcan possède trois usines en Ontario, la principale étant celle de Kingston qui, avec sa capacité de 41,000 tonnes, est la plus importante usine canadienne des dérivés de laluminium. Les autres, situées aux environs de Toronto, fabri-

1. Revue de l'Aluminium, 38 année, no 290, septembre 1961, p. 1008. 
quent des pièces coulées et divers articles manufacturés. Toutefois, l'expansion la plus spectaculaire de l'Alcan se fit sur la côte du Pacifique, à Kitimat', en Colombie-Britannique. Une ville fut créée de toutes pièces à l'extrémité amont du fjord de Douglas, à quelque 400 milles au nord de Vancouver. Doté d'un port de mer à eau profonde et bien abrité (le fjord s'encaisse dans la chaîne côtière jusqu'à 80 milles de l'océan), le site fut bien choisi, malgré son éloignement des régions habitées du littoral. Les travaux d'aménagement débutèrent en 1952 par la construction d'une centrale hydro-électrique, celle de Kémano, située sur les flancs d'un fjord voisin (Gardner). Cependant, les torrents qui drainent le versant occidental n'ont qu'un faible débit; c'est pourquoi il a fallu opérer une transfusion d'eau en provenance du versant opposé. On a transformé le cours supérieur de la Nechako (tributaire du Fraser) en un vaste réservoir perché à 2,800 pieds au-dessus du niveau marin. Puis on a foré un tunnel long de 10 milles à travers la chaîne pour amener l'eau aux turbines de la centrale, située à 210 pieds d'altitude en contrebas. On obtint ainsi une hauteur moyenne de chute d'environ 2,485 pieds. Sept turbines de 150,000 H.P. chacune y furent installées de 1954 à 1960, donnant une puissance aménagée de 1,050,000 H.P. D'autres seront ajoutées au fur à mesure des besoins. La centrale pourrait éventuellement être équipée pour produire deux millions de H.P. Elle est totalement enfouie sous terre afin d'être à l'abri moins d'une hypothétique catastrophe militaire que des intempéries du climat. La force est acheminée vers Kitimat par une ligne de transport à haute tension (300,000 volts) d'une cinquantaine de milles. Le tracé de cette ligne a posé de gros problèmes aux ingénieurs. On a renoncé à suivre le littoral des fjords, trop sinueux et parfois aux versants trop raides pour y fixer les pylônes. Elle enjambe directement la chaîne côtière en s'élevant jusqu'à 5,000 pieds d'altitude. Il fallait, en outre, parer au risque du verglas dans ces régions copieusement arrosées. Les expériences ont révélé que la glace s'accumulant sur les fils peut les alourdir de 15 à 20 livres au pied linéaire.

1. Noël Falaise, «Les travaux de Kitimat», Revue Canadienne de Géographie (Montréal), Vol. VI, 1952, pp. 12,18, 1 carte.

N.H. Richardson, eRégion de Kitimat:, dans Les ressources et notre avenir, Tome I, Ottawa, Imprimeur de la Reine, 1961, pp. 459-468, 2 cartes. 
L'usine elle-même de Kitimat fut terminée et mise en marche le 3 août 1954. Le choix du site s'imposait par l'espace disponible. Il consiste en une basse terrasse riveraine où l'on a pu localiser une usine d'électrolyse et prévoir son extension future entre le rivage de la mer et les montagnes recouvertes d'une forêt épaisse vers l'intérieur. Les quais en eau profonde sont parallèles à la rive et munis d'appareils automatiques de manutention. L'alumine est expédiée vers l'usine sur des tapis roulants semblables à ceux des élévateurs à grains'. L'usine d'électrolyse, composée de plusieurs immenses halls parallèles, fut dotée dès le début d'une capacité annuelle de 91,500 tonnes. On envisageait alors de la porter bientôt à 331,500 tonnes et plus tard à un demi-million. Ces prévisions ne se sont pas réalisées.

La ville de Kitimat est située à 5 milles de l'usine, vers l'inté. rieur, sur la rive gauche de la rivière Kitimat. Là, en effet, se trouvent des terrasses d'environ 300 à 400 pieds d'altitude, au bas de la montagne, assez étendues pour y disposer des aménagements urbains traditionnels. Ici, comme à Arvida, l'Alcan a bâti une ville selon les principes de l'urbanisme moderne. Sur la rive droite de la rivière, on a installé la gare et les voies du National Canadien. Kitimat est en effet relié au réseau canadien par un embranchement de 40 milles au départ de Terrace. On trouve autour de la gare quelques petites industries et des établissements de services. L'artère principale de Kitimat, la rue Haisla, se détache à angle droit de ce carrefour, franchit la rivière par un pont, aboutit aux édifices publics avant de se prolonger hors de la ville en direction de Terrace. Il existe trois quartiers domiciliaires: celui de Kildala au sud-ouest et deux au nord-est, celui de Nechako en bordure de la rue Haisla et celui de Whitesail, encore peu habité, plus au nord. Les rues sont tracées en courbes harmonieuses et les habitations sont isolées sur des pelouses gazonnées et fleuries. Des bosquets de conifères ont été.conservés ça et là. Est-ce une ville dite patronale (ou fermée) comme Arvida? Elle l'a été à ses tout débuts, certes, dans le sens où l'Alcan l'a bâtie à ses frais; mais on s'efforce d'appliquer ici une politique différente de celle qui a été pratiquée naguère à Arvida, en favorisant l'achat de maisons et terrains par les

1. Voir la planche 10 du dossier .Canadas, La Documentation française, Paris, no 5.218, octobre 1961, Etabli sous la direction de M. Raoul Blanchard. 
usagers. Une telle ligne de conduite n'a été suivie que depuis 1950 à Arvida. Kitimat fut érigée en municipalité dès son inauguration (1953) et l'Alcan encourage l'accession des citadins à la propriété privée. Elle se défend d'exercer une tutelle sur eux. Ceci est également vrai pour Arvida. Elle cherche en outre à attirer d'autres industries, ne serait-ce que pour leur vendre une partie de son excédent d'énergie électrique. De concert avec la société MacMillan, Bloedel and Powell River Ltd, elle a formé la Kitimat Pulp and Paper en vue d'implanter une usine de pâtes et papier. Elle détient les droits de coupe de la région; mais on a dû mettre le projet en veilleuse pour l'instant.

Kitimat est une ville planifiée, capable de loger éventuellement une population de 50,000 habitants. Elle en avait moins de 10,000 au recensement de 1956, et semble n'en renfermer guère plus de 7,000 aujourd'hui. L'usine emploie environ 2,000 travailleurs; sa capacité, avec 5 séries de cuves, n'est encore que de 192,000 tonnes. En 1956, l'Alcan a révélé que ses investissements pour Kitimat s'élevaient à 380 millions de dollars et qu'elle se proposait alors d'y injecter 130 autres millions. Elle visait à doter son usine d'une capacité de 555,000 tonnes, en 1959. La récession de 1958 l'a sans doute fait déchanter. Vers la fin de 1957, on a dû interrompre la construction de deux nouvelles séries de cuves et licencier un grand nombre d'ouvriers du bâtiment. La Société, en outre, joue de malheur. De fâcheuses infiltrations se sont produites dans un tunnel de Kemano en 1960. On a dû vidanger pour réparer les dégâts, donc interrompre la fusion à Kitimat du 19 juin au 12 septembre 1961. Bref, l'accident a coûté deux millions de dollars à la compagnie. Kitimat, d'autre part, est une ville isolée, malgré son beau cadre naturel de montagnes, lacs et parcs nationaux à proximité. On peut en sortir par le bateau, par le train ou par la route, mais Prince-Rupert est à 140 milles, Vancouver à 1,000 milles par la route ou 400 milles par avion (prix du transport: 80 dollars aller et retour). Le climat y est assez doux, $25^{\circ} \mathrm{F}$ en janvier, $62^{\circ} \mathrm{F}$ en juillet, mais fort pluvieux: 73 pouces de pluie et 16 pieds de neige par an. Toutefois, les citadins de Kitimat sont fiers de leur patrie, car ils en sont les pionniers. En sera-t-il de même pour les générations futures? Tout dépendra en définitive des conditions économiques. Advenant une crise, la ville se dépeuplera forcément. Au contraire, 
en période d'expansion, la confiance en l'avenir renaît, et l'Alcan aura eu raison, en somme, de voir grand, car le Canada peut espérer de nouveaux progrès dans ce domaine, comme en témoignent les projets d'expansion à Baie-Comeau. Il est même possible qu'une troisième entreprise vienne s'ajouter aux deux précédentes. Le groupe Harvey Aluminum Inc., de Californie, songerait à créer en Nouvelle-Ecosse une installation intégrée de production d'aluminium en y utilisant, croit-on, un procédé de réduction directe ${ }^{1}$.

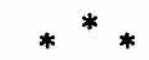

Avec une production de l'ordre de 700,000 tonnes métriques en 1960, le Canada semble conserver, comme auparavant, la seconde place dans le monde, loin cependant du premier producteur, les Etats-Unis. Celui-ci fournit en moyenne trois fois plus d'aluminium de première fusion que le Canada. Les principaux concurrents du Canada pour le second rang ont changé depuis la période d'avantguerre. Avec l'aménagement d'Arvida, en 1927, notre pays avait surpassé la France et l'Allemagne, mais celle-ci prit les devants entre 1934 et 1939, alors qu'elle s'outillait pour la seconde guerre mondiale. Le Canada reprit le second rang durant cette guerre et l'a gardé jusqu'en 1959, année où il fut dépassé par un nouveau concurrent, l'Union Soviétique (voir tableau II), dont les progrès sont foudroyants. Venu tardivement à cette industrie (1932), ce pays a non seulement dépassé le nôtre en 1959, mais il se propose de ravir la première place aux Etats-Unis dès 1965. Les deux premiers centres importants furent, dans la partie européenne de l'U.R.S.S., Volkhov, près de Leningrad, et Zaporoje, sur le Dniéper, alimentés en minerai par les gisements de Tikhvin, où une nouvelle usine de traitement de la bauxite s'ajoutera bientôt à Pikalevo. Plus tard, on découvrit d'autres gisements ayant une teneur plus élevée que les précédents en bauxite dans l'Oural, ceux de Kamensk-Ouralski, près de Sverdlovsk, et de Severoouralsk, plus au Nord, où des usines d'électrolyse furent établies. La migration de l'industrie s'est poursuivie encore plus à l'Est, le long du cours supérieur de l'Irtych, à Pavlodar, où une usine de 300,000 tonnes est prévue pour utiliser la bauxite d'Arkalyk; puis le long du transsibérien

1. Revue de l'Aluminium, 38 anné, septembre 1961, p. 1008. 
L'ACTUALITE ECONOMIQUE

Tableau II

Production mondiale de l'aluminium ${ }^{1}$ et capacité

(en milliers de tonnes métriques)

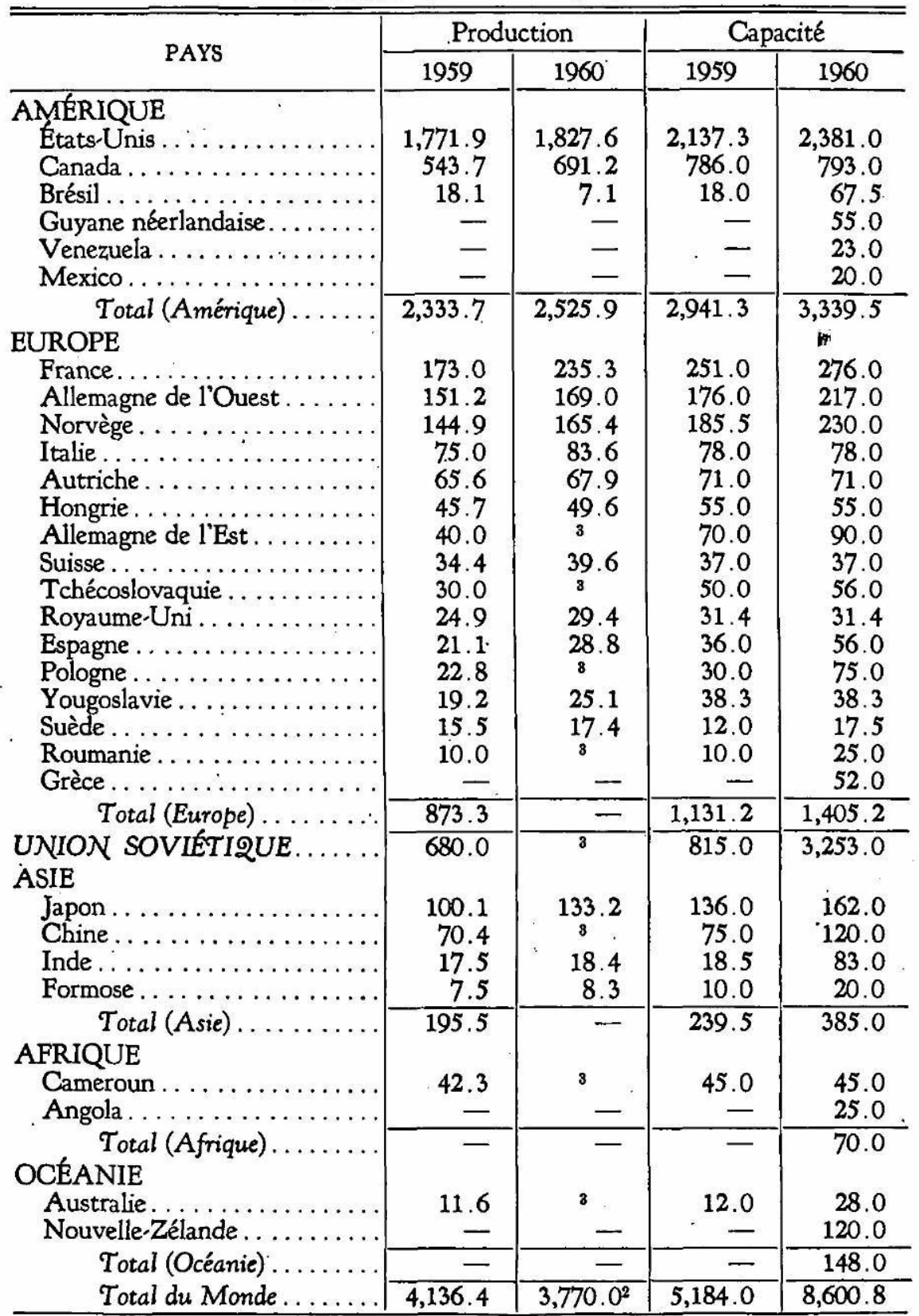

1. De première fusion seulement.

2. Sauf U.R.S.S. et Chine.

3. Non publié. 


\section{L'ALUMINIUM AU CANADA}

pour exploiter les gisements de Goryachegorsk et de Kyakhta. Une usine de traitement de 800,000 tonnes est en construction à Atchinsk pour alimenter les nouvelles usines d'électrolyse de Krasnoïarsk $(300,000$ t.) et d'Irkoutsk $(300,000$ t.) qui recevront leur énergie de centrales sur l'Angara, tribùtaire de l'Yenisei. Enfin une usine de traitement est prévue en Azerbaïdjan, à Kirovabad, et une usine d'électrolyse de 33,000 tonnes a commencé de produire, en 1959, à Stalingrad (Volgograd). L'Union Soviétique dispose désormais d'une capacité totale de 815,000 tonnes, donc supérieure à celle du Canada ${ }^{1}$. Elle vise à quadrupler sa production en 1965, donc à surpasser celle des Etats-Unis. Les plus proches concurrents du Canada demeurent la France, l'Allemagne de l'Ouest, la Norvège et l'Italie, dont la production globale n'arrive cependant pas à égaler celle de notre pays.

Toutefois, même si le Canada n'est plus le second du monde comme producteur, il reste le premier comme exportateur d'aluminium (tableau III). Notre pays, en effet, exporte plus des quatre cinquièmes du volume qu'il fabrique et cela principalement à l'état brut ou semi-ouvré (lingots, barres, feuilles, etc.). Bien que la consommation nationale ait presque doublé depuis dix ans $(65,200$ tonnes en 1950, 102,000 tonnes en 1960), le Canada dispose de forts excédents pour les marchés extérieurs. Il n'exportait guère plus de 200,000 tonnes vers 1950, aujourd'hui il en exporte plus de 500,000. Exprimé en tonnes métriques, ce volume fut de 482,000 tonnes en 1959, et de 528,500 tonnes en 1960.

Son plus proche concurrent sur le marché mondial fut, jusqu'en 1960, la Norvège, troisième producteur d'Europe (voir tableau II) dont la consommation nationale est forcément réduite. En effet, ayant produit 165,000 tonnes d'aluminium brut, la Norvège en a exporté 143,500 tonnes en 1960. La capacité de ses usines est d'environ 188,000 tonnes et sera augmentée d'ici cinq ans à 230,000 tonnes et peut-être à plus de 300,000 tonnes en 1970. La principale société (étatisée) est l'Ardal og Sunndal Verke qui dispose d'une usine d'électrolyse de 50,000 tonnes à Sunndal, de deux autres à

1. Le Minerals Yearbook 1959 (voir la bibliographie) donne la liste de tous les producteurs d'alumine du monde, pp. 233.234, et d'aluminium, pp. 171.173, ainsi que la capacité annuelle des usines. 
Ardal $(36,000$ et 30,000 t.) où une quatrième $(40,000$ t.) est en construction. Trois autres sociétés ont des installations (4 usines totalisant 72,000 t.) plus modestes, mais de nouvelles entreprises projettent de s'établir, entre autres la Société Norvégienne de l'Azote. Ces usines importent leur alumine de l'étranger. Ardal, par exemple, a conclu, en 1958, un arcord de troc avec Aluminum Limited qui doit lui fournir 4,100,000 tonnes d'alumine en vingt ans, contre de l'aluminium en lingots.

La Norvège exporte trois fois moins d'aluminium que le Canada. Les pays du Marché commun, pris ensemble, surpassent la Norvège. Il est vrai que ceuxci font d'abord du commerce entre eux et vendent surtout des produits ouvrés, comme c'est le cas pour le Royaume-Uni. En fait, le concurrent le plus redoutable du Canada pour l'aluminium brut n'est plus la Norvège, en 1960, mais les Etats-Unis (voir tableau IV), dont les exportations se sont brus-

\section{Tableau III}

Principaux exportateurs d'aluminium dans le monde

\begin{tabular}{|c|c|c|c|c|}
\hline \multirow[b]{2}{*}{ PAYS } & \multicolumn{2}{|c|}{1959} & \multicolumn{2}{|c|}{1960} \\
\hline & $\begin{array}{l}\text { Volume } \\
\text { (en milliers } \\
\text { de tonnes } \\
\text { métriques) }\end{array}$ & $\begin{array}{l}\text { Valeur } \\
\text { (en millions } \\
\text { de dollars) }\end{array}$ & $\begin{array}{l}\text { Volume } \\
\text { (en milliers } \\
\text { de tonnes } \\
\text { métriques) }\end{array}$ & $\begin{array}{l}\text { Valeur } \\
\text { (en millions } \\
\text { de dollars) }\end{array}$ \\
\hline 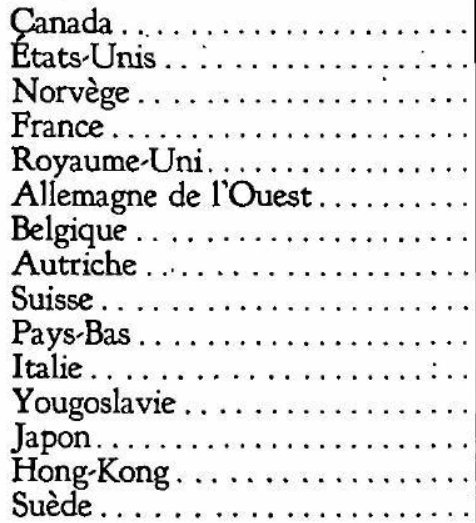 & $\begin{array}{r}482.0 \\
114.4^{1} \\
136.7 \\
68.8 \\
54.0 \\
34.1 \\
35.2 \\
50.2 \\
-\overline{9} \\
9.8 \\
16.2 \\
10.0 \\
9.5 \\
-\end{array}$ & $\begin{array}{r}235.9 \\
67.8 \\
66.9 \\
37.2 \\
44.5 \\
34.5 \\
24.1 \\
26.3 \\
11.6 \\
9.9 \\
7.3 \\
5.9 \\
-\end{array}$ & $\begin{array}{l}528.5 \\
261.0^{1} \\
143.5 \\
98.0 \\
54.0 \\
40.7 \\
46.5 \\
35.2 \\
24.6 \\
9.8 \\
6.7 \\
14.5 \\
10.3 \\
11.8 \\
6.6\end{array}$ & $\begin{array}{r}276.5 \\
147.9 \\
72.2 \\
56.8 \\
48.2 \\
40.6 \\
32.5 \\
21.0 \\
22.7 \\
11.0 \\
5.3 \\
10.4 \\
6.4 \\
6.2 \\
4.9\end{array}$ \\
\hline
\end{tabular}

1. Estimé. 


\section{L'ALUMINIUM AU CANADA}

Tableau IV

\section{Répartition des usines d'électrolyse d'alumine aux États-Unis}

(en milliers de tonnes faibles)

\begin{tabular}{|c|c|c|c|}
\hline \multirow{2}{*}{ Usines } & \multicolumn{2}{|c|}{ Capacité } & \multirow{2}{*}{$\frac{\text { Production }}{1959}$} \\
\hline & 1959 & 1960 & \\
\hline 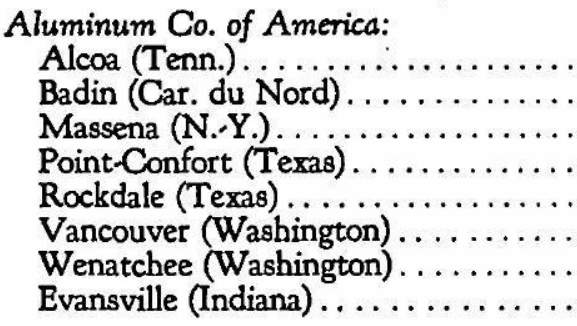 & $\begin{array}{r}157.1 \\
47.2 \\
118.0 \\
120.0 \\
150.0 \\
97.5 \\
108.5 \\
-\end{array}$ & $\begin{array}{r}157.1 \\
47.2 \\
150.0 \\
140.0 \\
150.0 \\
97.5 \\
108.5 \\
150.0\end{array}$ & $\begin{array}{l}\bar{z} \\
\bar{z} \\
\bar{z}\end{array}$ \\
\hline Sous-total......... & 798.3 & $1,000.3$ & 627.0 \\
\hline 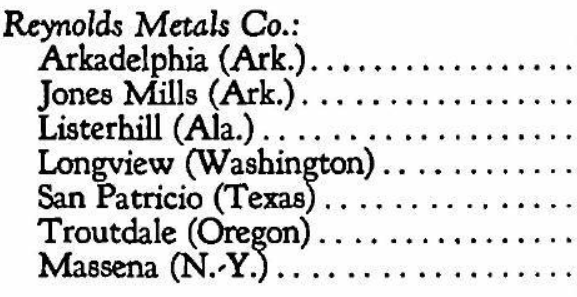 & $\begin{array}{r}55.0 \\
109.0 \\
190.0 \\
60.5 \\
95.5 \\
91.5 \\
33.0\end{array}$ & $\begin{array}{r}55.0 \\
109.0 \\
190.0 \\
60.5 \\
95.0 \\
91.5 \\
100.0\end{array}$ & $\begin{array}{l}= \\
= \\
\bar{z} \\
=\end{array}$ \\
\hline Sous-total ................... & 634.0 & 701.0 & 545.1 \\
\hline 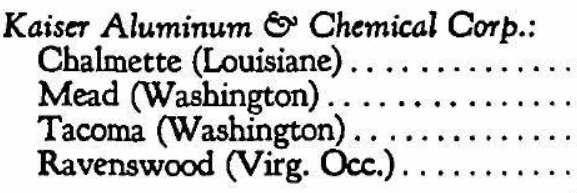 & $\begin{array}{r}247.5 \\
176.0 \\
41.0 \\
72.5\end{array}$ & $\begin{array}{r}247.5 \\
176.0 \\
41.0 \\
145.0\end{array}$ & $\bar{z}$ \\
\hline Sous.total............ & 537.0 & 609.5 & 488.8 \\
\hline $\begin{array}{l}\text { Ormet Corporation: } \\
\text { Clarington (Ohio) ..... }\end{array}$ & 144.0 & 180.0 & \\
\hline $\begin{array}{l}\text { Anaconda Aluminum Co.: } \\
\text { Columbia Falls (Mont.). }\end{array}$ & 60.0 & 62.5 & 292.1 \\
\hline $\begin{array}{l}\text { Harvey Aluminum Inc.: } \\
\text { The Dalles (Oregon). }\end{array}$ & 54.0 & 60.0 & \\
\hline Total... & $2,194.3$ & $2,613.3$ & $1,953.0$ \\
\hline
\end{tabular}


quement élevées depuis 1958. Elles furent de 52,712 tonnes faibles valant 24.2 millions de dollars, à cette date; elles doublèrent en 1959 et encore en 1960. Ceci résulte évidemment d'une expansion considérable de la production depuis dix ans (elle a triplé) et de l'intérêt que portent les trois principales entreprises aux marchés extérieurs. L'Alcoa, par exemple, s'est alliée à Imperial Chemical Industries pour former en Grande-Bretagne le groupe Almin qui fabrique divers articles à partir de l'aluminium de rebut. Elle s'intéresse en outre à d'autres entreprises au Japon et en Amérique latine auxquelles elle fournit l'aluminium brut. Reynolds, d'autre part, semble être la société américaine qui a placé les plus forts investissements à l'étranger dans ce domaine. Elle vient d'acquérir (1959) une participation importante dans la société British Aluminum, le seul producteur anglais d'aluminium brut, et dont les fabriques manufacturent environ le tiers des produits ouvrés du pays. Par le truchement d'un holding, Reynolds International Inc., la même société contrôle une part plus ou moins grande des industries d'aluminium ailleurs dans le monde: au Canada (voir tableau I), en Amérique latine (Mexique, Colombie et Venezuela), aux Philippines et en Grèce. Enfin Kaiser Aluminum, à l'instar de ses rivales, participe aux projets d'expansion de l'aluminium dans certains pays du Commonwealth, tels que la Grande-Bretagne, l'Australie, la Nouvelle-Zélande, l'Inde et Ghana, ainsi qu'en Espagne et en Argentine.

Or, ce procédé, qui consiste en somme à se créer une clientèle à l'étranger par des filiales ou sociétés apparentées, c'est celui que la plus grande société canadienne, l'Alcan, a poursuivi systématiquement depuis sa fondation, et surtout durant la période d'aprèsguerre. Nous en avons la preuve dans l'éloquent tableau $\mathrm{V}$ qui remet à jour celui que nous avions fait en 1946 et qui était déjà fort impressionnant à l'époque ${ }^{1}$. Nous y ajoutons le groupe Reynolds qui a surgi depuis. Le rapport annuel, par exemple, de l'Aluminum Limited est illustré d'une mappemonde et de paysages coloriés dans les cinq parties du monde.

1. B. Brouillette, «L'Aluminium au Saguenay ^, op. cit., pp. 444-446. 


\title{
Tableau V
}

\section{Répartition géographique des entreprises de l'alu- minium établies au Canada, en 1959, et de leurs filiales à l'étranger}

\author{
A. GROUPE DE L'ALUMINIUM LIMITED
}

(fondé en 1928. Siège social à Toronto 1928-1939, et à Montréal depuis 1939)

\section{SES FILIALES}

\section{I - EN AMERIQUE DU NORD}

(valeur de l'actif (1960) moins amortissements: 936,000,000 dollars)

\section{CANADA}

1) Aluminum Co. of Canada Ltd. (participation 100 p.c.)

Capacité (fondé en 190G. Siège social à Montréal)

a) usines d:

- Arvida (P.Q.): Usine de traitement de la bauxite 1,250,000 t.

Usine d'électrolyse.......... $367,000 \mathrm{t}$.

Produits chimiques......... $15,900 \mathrm{t}$.

- Kitimat (C.-B.): Usine d'électrolyse (1954)... 192,000 t.

- Isle-Maligne (P.Q.): Usine d'électrolyse...... 115,000 t.

- Shawinigan (P.Q.): Usine d'électrolyse (1901).. $\quad 70,000 \mathrm{t}$.

Tréfilerie............. $28,000 \mathrm{t}$.

- Beauharnois (P.Q.): Usine d'électrolyse...... 38,000 t.

- Kingston (Ont.): Usine d'articles semi-ouvrés et ouvrés (dont la capacité sera portée à 60,000 tonnes prochainement) .............

- Etobicoke (Ont.): Usine de pièces coulées......

- Vancouver (C.-B.): Tréfilerie.............. 4,800 t.

- Wakefield (P.Q.): Produits chimiques

b) centrales hydro-électriques:

- Sur le Saguenay: Shipshaw (1942-43) ....... 1,200,000 H.P. Chute-à-Caron (1931-41) .... 300,000 H.P.

- Sur la Péribonka: Chute-da-la-Savane (1954) ... 285,000 H.P. Chute-du-Diable (1953) ..... 275,000 H.P. Chute-des-Passes (1959-61) . $1,000,000$ H.P

- Sur la Nechako: Kémano (1954-57)........ 1,050,000 H.P.

- Autre centrale (voir plus bas): Isle-Maligne (1925-37)

2) Aluminum Goods Ltd. (participation 100 p.c.)

- Usine d'articles manufacturés.

3) Aluminium Laboratories Ltd. (participation 100 p.c.)

(fondé en 1936. Siège social à Montréal)

- Services techniques

- Centres de recherches à Kingston (Ont.), à Arvida (P.Q.), à Banbury (Angleterre).

4) Newfoundland Fluorspar Ltd. (participation 100 p.c.)

(fondé en 1939. Siège social à Saint-Jean, Terre-Neuve)

- Exploitation des gisements de spath fluor a St. Lawrence, Terre-Neuve. 


\section{L'ACTUALITE ECONOMIQUE}

5) Saguenay Skipping Ltd. (participation 100 p.c.)

(fondé en 1957. Siège social à Montréal)

- Service de transport maritime et d'affrètement de navires.

6) Saguenay Terminals Ltd. (participation 100 p.c.)

(fondé en 1904 et 1929. Siège social à Montréal)

- Entrepôts et installations portuaires de Port-Alfred, terminus de la navigation sur le fjord du Saguenay.

7) La Cie du Chemin de Fer Roberval-Saguenay (participation 100 p.c.)

(fondée en 1911. Siège social à Arvida, P.Q.)

- Voie ferrée de 19 milles reliant Port-Alfred à Arvida.

8) La Cie du Chemin de Fer Alma et Jonquieres (participation 93.6 p.c.) (fondée en 1912. Siège social à Montréal)

- Voie ferrée de 10 milles reliant l'Isle-Maligne au réseau du National Canadien, près d'Hébertville.

9). Saguenay Power Co. Ltd. (participation 93.6 p.c.)

(fondé en 1924. Siège social à Montréal)

- Centrale hydro-électrique de l'Isle-Maligne, sur le Saguenay (1925-37).....................

10) Saguenay Transmission Co. Ltd. (participation 93.6 p.c.) (fondé en 1926. Siège social à Montréal)

- Réseau de distribution en gros d'électricité au Saguenay et hors de la région.

11) La Cie Electrique du Saguenay (participation 93.6 p.c.) (fondée en 1927. Siège social a Chicoutimi)

- Réseau de distribution au détail de l'électricité au Saguenay et hors de la région.

\section{ETATS-UNIS}

1) Aluminium Itd.

- Projet de laminoirs d'une capacité de $100,000 \mathrm{t}$. a établir près d'Oswego, Etat de New-York, avec la participation des sociétés Bridgeport Brass, Cerro de Pasco Corp. et Scovill Manufacturing Co. Cette usine sera alimentée en aluminum brut par Alcan.

\section{II - EN AMERIQUE DU SUD, AUX ANTILLES ET AU MEXIQUE}

(valeur de l'actif (1960) moins amortissements: 186,000,000 dollars)

\section{GUYANE BRITANNIQUE}

1) Demerara Bauxite Co. Lid. (participation 100 p.c.)

(fondé en 1916. Siège social à Georgetown, Guyane britannique)

- Exploitation de gisements de bauxite; usine locale de traitement projetée.

2) Sprostons Ltd. (participation 100 p.c.)

(fondé en 1898 et 1952. Siège social à Georgetown, Guyane britannique)

- Transport, commerce, construction. 


\section{L'ALUMINIUM AU CANADA}

\section{JAMA IQUE}

Capacité

actuelle

3) Alumina Jamaica Ltd. (participation 100 p.c.)

(fondé en 1943. Siège social à Kirkvine, Jamaïque)

- usines de traitement alimentées par des gisements de bauxite en Jamaique; activités agricoles et pastorales.......................

4) Sprostons (Jamaīca) Ltd. (participation 100 p.c.)

(fondé en 1952. Siège social à Kingston, Jamaique)

- Gestion de Port-Esquivel, commerce, construction.

5) Alcan Products of Jamaïca Ltd. (participation 100 p.c.)

(fondé en 1959. Siege social à Kingston, Jamaĩque)

- Usine de tôles ondulés et de meubles.

\section{TRINIDAD}

6) Chaguaramas Terminals Ltd. (participation 100 p.c.)

(fondé en 1942. Siège social a Montréal)

- Transbordement de la bauxite, gestion d'entrepots et installations portuaires à Trinidad.

7) Sprostons (Trinidad) Ltd. (participation 100 p.c.)

(fondé en 1960. Siège social à Port of Spain, Trinidad)

- Usine de tôles ondulées et commerce.

\section{BRESIL}

8) Aluminio Minas Gerais S.A. (participation 100 p.c.)

(fondé en 1934. Siège social à Saramenha, près d'Ouro Preto, Brésil)

- Complexe industriel intégré: extraction de la bauxite brésilienne.

- Usine de traitement de la bauxite...............

- Usine d'électrolyse.......................

- Ferro-alliage, énergie électrique.

$568,000 \mathrm{t}$.

9) Aluminio do Brasil S.A. (participation 100 p.c.)

(fondé en 1940. Siège social à Sao Paulo, Brésil)

- Usine d'articles semi-ouvrés et ouvrés; nouveaux laminoirs en 1961.

\section{ARGENTINE}

10) Antonio Vernocchi S.A.I.C.I.F. (participation 76 p.c.)

(fondé en 1940. Siège social à Buenos-Aires)

- Usine de feuilles minces d'aluminium à BuenosAires; projets d'expansion.

11) Aluminio Argentina, S.A.C.I. (participation 100 p.c.)

(Siège social à Buenos-Aires)

- Laminoirs.

\section{COLOMBIE}

12) Aluminio Alcan de Colombia S.A. (participation 73.13 p.c.) (fondé en 1960. Siège social à Cali, Colombie)

- Usines de tôles et de profilés en aluminium à Yumbo; laminoirs projetés.

\section{URUGUAY}

13) Aluminio del Uruguay S.A. (participation 70.9 p.c.)

(fondé en 1935. Siège social à Montevidéo, Uruguay)

- Usines de tôles, profilés et feuilles minces; important programme dexpansion. 


\section{L'ACTUALITÉ ÉCONOMIQUE}

MEXIQUE

Capacité actuelle

14) Aluminio Industrial Mexicano S.A.(participation 60.9 p.c.) (fondé en 1944. Siège social à Tulpetlac, Mexico)

- Usine aux environs de Mexico, de tôles, feuilles minces, profilés, alpâte. Laminoirs modernisés en 1960.

15) Fluoresqueda, S.A. (participation 33.3 p.c.)

(fondé en 1956. Siège social à Agua Prieta, Sonora, Mexique)

- Exploitation de gisements de spath fluor.

\section{III - EN EUROPE}

(valeur de l'actif (1960) moins amortissements: $157,000,000$ dollars)

\section{ROYAUME-UNI}

1) Alcan Industries Ltd. (participation 100 p.c.)

(fondé en 1909. Siège social à Londres)

usines à:

- Rogerstone: laminoirs.

75,000 t.

(tôles, profilés, pièces moulées et forgées, barres, fils, alpáte).

- Succursale en Nouvelle-Zélande: laminoirs (1961)..

2) Alcan Enfield Alloy Ltd. (participation 50 p.c.)

(fondé en 1960. Siège social à Enfield, Middlesex)

- Usine d'alliages de second laminage, près de St. Albans (Hertfordshire).

\section{FRANCE}

3) Aluminium Alcan de France (participation 100 p.c.)

(fondé en 1926. Siège social à Paris VIII')

- Usine d'alpâte et profilés à Lucé, près de Chartres.

4) Societé anonyme de Bauxites et Alumines de Provence (participation 100 p.c.)

(fondé en 1915. Siège social à Paris)

- Exploite des gisements de bauxite dans le Midi de la France, à Aix-en-Provence.

5) Bauxites du Midi (participation 100 p.c.)

(fondé en 1912. Siège social à Paris)

- Exploitation de gisements de bauxite à Brignoles.

- Vaste projet de développement en Guinée $(175,000,000$ dollars $)$ à Boké dont la réalisation fut abandonnée en 1961 .

\section{ALLEMAGNE DE L'OUEST}

6) Aluminiumwerke Nürnberg G.m.b.H.(participation 100 p.c.)

(fondé en 1924 et 1934. Siège social à Nuremberg)

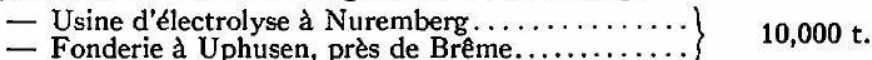

7) Aluminiumwerke Göttingen G.m.b.H.(participation 100 p.c.)

(fondé en 1926. Siège social à Göttingen)

- Laminoirs à Göttingen. 


\section{L'ALUMINIUM AU CANADA}

SUISSE

Capacite

actuelle

8) Aluminiumwerke A.G. Rorschach (participation 100 p.c.) (fondé en 1929. Siège social à Rorschach)

- Usine de tôles et feuilles minces à Rorschach, près du lac de Constance; projets d'expansion considérable (1961).

9) Fabrique d'Emballages Métalliques S.A. (participation 33.3 p.c.)

(fondé en 1935. Siège social à Fribourg)

- Usine d'emballages d'aluminium vendant en Suisse, France et Pays-Bas.

ITALIE

10) Alcan Aluminio Italiano S. p. A. (participation 100 p.c.) (fondé en 1917. Siège social à Ivrea, près de Turin)

- Usine de première et seconde fusion à Borgofranco.

- Energie hydro-électrique.

\section{SUEेDE}

11) A.B.SvenskaAluminium-kompaniet (participation 50 p.c.) (fondé en 1934. Siège social a Stockholm)

- En 1961, participation cédée à la société suédoise A.B. Svenska Metallwerken.

- Usines d'électrolyse.

$16,700 \mathrm{t}$.

- Usine de traitement de la bauxite.

\section{NORVËGE}

12) A/S Norsk Aluminium Co. (participation 50 p.c.)

(fondé en 1923. Siège social à Oslo)

— Usine d'électrolyse.

- Usine de traitement d Heyanger, sur le Sognfjord. .

- Énergie électrique.

13) Det-Norske Nitridaktieselskap (participation 50 p.c.)

(fondé en 1912. Siège social à Oslo)

- Usines d'électrolyse à Tyssedal................

- Usine d'électrolyse à Eydehavn.................

14) [A /S Nordisk Aluminiumindustri (participation 50 p.c.)

(fondé en 1923. Siège social à Oslo)

- Usine de tôles, barres, pièces moulées, articles ménagers, à Holmestrand.

- Usine à Vesthöy en expansion.

- Usine d Hoyanger.

\section{DANEMARK}

15) Dansk Aluminium Industri A/S (participation 50 p.c.) (fondé en 1918. Siège social à Copenhague)

- Usine d'articles ménagers, chaudonnerie.

\section{$P A Y S-B A S$}

16) N.V. Nederlandsche Aluminium Maatschappij (participation 40 p.c.)

(fondé en 1938. Siège social à Amsterdam)

- Usine à Utrecht de tôles, profilés, feuilles minces, alpâte. 


\section{L'ACTUALITÉ ECONOMIQUE}

ESPAGNE

17) Aluminio Iberico S.A. (participation 42.29 p.c.)

(fondé en 1951. Siège social à Madrid)

- Usine de tôles, profilés, barres, cables a Alicante; expansion en 1960.

\section{BELGIQUE}

18) Aluminium Raeren S.A. (intérêt majoritaire)

(fondée en 1961)

- usine de filage à la presse à Raeren.

\section{IV - DANS LE RESTE DU MONDE}

(valeur de l'actif (1960) moins amortissements: $80,000,000$ dollars)

\section{AFRIQUE:}

UNION SUD-AFRICAINE

1) Alcan Aluminium of South Africa Ltd. (participation 100 p.c.)

(fondé en 1940. Siège social à Pietermaritzburg, Natal)

- Fabrication et vente de toles, feuilles minces, profilés; expansion prévue (1961). Usine située près de Johannesburg.

\section{NIGERIA}

2) Nigeria Aluminium Products Ltd. (participation 60 p.c.) (fondé en 1959. Siège social à Lagos)

- Fabrication de tôles ondulées a Lagos et Port-Harcourt.

3) Tover Aluminium (Nigeria) Ltd. (participation 25.6 p.c.) (fondé en 1959. Siège social à Lagos)

- Fabrique d'articles ménagers.

4) Alcan Aluminium of Nigeria Ltd.

(fondé en 1961. Siège social à Port-Harcourt)

- Laminoirs.

\section{GHANA}

5) Ghana Aluminium Products Ltd. (participation 60 p.c.) (fondé en 1959. Siège social à Accra)

- Fabrique de tôles, fenêtres, meubles a Tema; autres usines projetés.

\section{ASIE:}

\section{$I N D E$}

6) Indian Aluminium Co. Ltd. (participation 65 p.c.) (fondé en 1938-1945. Siège social à Calcutta)

- Extraction de bauxite.

- Usine de traitement a Muri.

- Usines d'électrolyse à Hirakud et Alwaye.........

- Usines de tôles, alpate, profilés à Alupuram.

- Laminoirs à Belur. 


\section{L'ALUMINIUM AU CANADA}

MALA ISIE

Capacité

actuelle

7) Southeast Asia Bauxites Lld. (participation 75 p.c.)

(fondé en 1955. Siège social à Montréal)

- Extraction de la bauxite.

8) Alcan Malayan Aluminium Co. Ltd.

(fondé en 1960. Siège social à Kuala Lumpur)

- Laminoirs projetés en 1961.

\section{JAPON}

9) Nippon Light Metal Co. Ltd. (participation 50 p.c.)

(fondé en 1939. Siège social à Tokyo)

- Usine de traitement a Shimizu.............. 180,000 t.

- Usines d'électrolyse à Kambara et Niigata....... 68,000 t.

- Energie électrique. Participation de 70 p.c. dans trois usines d'articles semi-ouvrés.

10) Tokyo Aluminium K.K. (participation 50 p.c.)

(fondé en 1931. Siège social à Osaka)

- Usine de tôles, feuilles minces, alpâte.

\section{SARAWAK}

11) Sematan Bauxite Ltd. (participation 33.3 p.c.)

(fondé en 1955. Siège social à Kuching)

- Exploitation de gisements de bauxite.

\section{AUSTRALIE}

12) Australian Aliminium Co. Ltd. (participation 50 p.c.)

(fondé en 1936. Siège social à Sydney, N.G.S.)

- Fabrique de toles, profilés, alliages.

13) Aluminium Foils (Australia) Pty Ltd. (participation 50 p.c.) (fondé en 1957. Siège social à Cabramatta, N.G.S.)

- Fabrique de feuilles minces, inaugurée en 1960....

\section{B. GROUPE REYNOLDS}

1) Canadian British Aluminium Co. Ltd.

(fondé en 1955. Siege social a Montréal)

- Entreprise contrôlée par la British Aluminium Co. Ltd (Angleterre) dans une proportion de 60 p.c., elle-même contrôlée par Reynolds Metal (ÉtatsUnis) et Tube Investments (Angleterre).

- Baie-Comeau (P.Q.): usine d'électrolyse (1957) (capacité projetée: 180,000 t.) $\ldots \ldots \ldots \ldots \ldots \ldots$.

Energie électrique fournie par:

2) Manicouagan Power Co. (participation 40 p.c.)

(fondée en 1949. Siège social à Montréal)

- McCormick (P.Q.): centrale hydro-électrique sur la et par Manicouagan (1952-57) . . . 25, 25, 000 H.P.

Hydro-Quebec: Centrale hydro-électrique de Bersimis I., 1,200,000 H.P.

3) Phillips C.B.A. Conductors Lld. (participation 100 p.c.)

(fondé en 1958. Avec Phillips Electrical Co.)

- Brockville (Ont.): tréfilerie projetée. 
4) Reynolds Aluminum Co. of Canada Ltd.

(fondé en 1955, a succédé à Dominion Foils, 1949. Siège social à Montréal. Société contrôlée par Reynolds Metal (Etats-Unis).

- Cap-de-la-Madeleine (P.Q.): usine d'articles manufacturés en aluminium (matériel d'emballage et matériaux de construction) . . . . . . . . . . . . . . .

$17,000 \mathrm{t}$.

5) Reynolds Aluminum Container Ltd. (participation 60 p.c.) (fondé vers 1958. Siège social à Toronto)

- Toronto: usine de clinquants pour servir d'emballage aux aliments congelés.

6) Aluminum Extruders Ltd.

(siège social à Ste-Thérèse, P.Q.)

- filage à la presse.

Connaissant la production canadienne, nous devons maintenant suivre les courants commerciaux d'abord des matières premières en direction du Canada, ensuite des produits fabriqués, exportés en majeure partie. La bauxite, la cryolithe et la fluorure sont les trois principaux minéraux qu'on utilise pour faire de l'aluminium. La première est de beaucoup la plus importante, les autres ne servent que de fondants. Aucun gisement de bauxite n'existe au Canada, car ce minerai provient de latérites à forte concentration d'alumine, qui se sont formées surtout dans les pays à climat tropical par l'altération subaérienne et continentale des roches silicatées. Le Canada importe donc cette matière première en totalité sous forme soit de bauxite brute ou d'alumine. Le volume de telles importations varie selon les besoins de l'industrie (graphique II). Il fut de 2 millions et quart de tonnes en 1959, et de près de 3 millions en 1960. La valeur (tableau VI) fut de 36 millions de dollars en 1959, et de 45 millions en 1960. La majeure partie vient des pays tropicaux d'Amérique (Guyane britannique et Jamaïque), le reste d'Afrique et du Midi de la France.

En valeur, la Jamaique se place au premier rang pour la simple raison qu'elle nous expédie de l'alumine (produit semi-ouvré) et non de la bauxite. Celle-ci vaut dix fois moins cher à la tonne, soit 5.50 dollars contre plus de 60 dollars pour l'autre. Pourquoi alors ne pas tout importer sous forme de bauxite? C'est ce qu'on faisait autrefois, mais il n'existe d'usine de traitement de la bauxite qu'à 
Arvida, les usines d'électrolyse de Baie-Comeau et de Kitimat utilisant l'alumine comme matière première. D'ailleurs, ce sont des filiales de l'Alcan qui font elles-mêmes l'extraction de la bauxite et la transforment en alumine. En Guyane britannique, la Société Demerara Bauxite exploite de vastes gisements en carrières à ciel ouvert, dont les réserves connues sont de 80 millions de tonnes (70 millions de réserves possibles). Les seules opérations consistent à éliminer la silice et à assécher le minerai qui est expédié comme bauxite sèche (moins de 15 p.c. d'eau) ou comme bauxite calcinée. La société projette de construire une usine de traitement de 245,000

Tableau VI

Les importations de bauxite et d'alumine au Canada

\begin{tabular}{|c|c|c|c|c|}
\hline \multirow{3}{*}{ En provenance de } & \multicolumn{2}{|c|}{1959} & \multicolumn{2}{|c|}{1960} \\
\hline & Volume & Valeur & Volume & Valeur \\
\hline & $\begin{array}{l}\text { (en tonnes } \\
\text { faibles) }\end{array}$ & $\begin{array}{l}\text { (en milliers } \\
\text { de dollars) }\end{array}$ & $\begin{array}{l}\text { (en tonnes } \\
\text { faibles) }\end{array}$ & $\begin{array}{l}\text { (en milliers } \\
\text { de dollars) }\end{array}$ \\
\hline $\begin{array}{l}\text { AMERIQUE } \\
\text { Jamaique } . . . . . . . . . . . . . . . . \\
\text { Guyane britannique ......... } \\
\text { Surinam (Guyanenéerlandaise) } \\
\text { Etats-Unis (ports du Pacifique) }\end{array}$ & $\begin{array}{r}301,050 \\
1,338,035 \\
292,285 \\
13,720\end{array}$ & $\begin{array}{r}190,722 \\
87,299 \\
28,619 \\
11,350\end{array}$ & $\begin{array}{r}418,180 \\
1,684,500 \\
350,405 \\
15,435\end{array}$ & $\begin{array}{r}265,002 \\
97,155 \\
40,491 \\
11,762\end{array}$ \\
\hline Total de l'Amérique...... & $1,945,090$ & 317,990 & $2,468,520$ & 414,410 \\
\hline $\begin{array}{l}\text { AFRIQUE } \\
\quad \text { Guinée (ex. A.O.F.) ....... } \\
\text { Union Sud-Africaine . . . . }\end{array}$ & $\begin{array}{r}264,890 \\
-\end{array}$ & $\begin{array}{r}15,424 \\
-\end{array}$ & $\begin{array}{r}499,985 \\
115\end{array}$ & $\begin{array}{r}27,939 \\
91\end{array}$ \\
\hline Total de l'Afrique........ & 264,890 & 15,424 & 500,100 & 28,030 \\
\hline $\begin{array}{l}\text { EUROPE } \\
\text { France (ports de la } \\
\quad \text { Méditerranée) ........... } \\
\text { Royaume.Uni et autres ..... }\end{array}$ & $\begin{array}{r}47,490 \\
-\end{array}$ & $\begin{array}{r}26,113 \\
48\end{array}$ & $\begin{array}{r}8,430 \\
20\end{array}$ & $\begin{array}{r}4,587 \\
62\end{array}$ \\
\hline $\begin{array}{l}\text { Total de l'Europe } \ldots \ldots \ldots \\
\text { OCEANIE } \\
\text { Australie } \ldots \ldots \ldots \ldots \ldots \ldots\end{array}$ & 47,490 & 26,161 & 8,450 & 4,649 \\
\hline Total des importations.... & $2,257,470$ & 359,575 & $2,982,870$ & 450,434 \\
\hline
\end{tabular}


L'ACTUALITE ECONOMIQUE

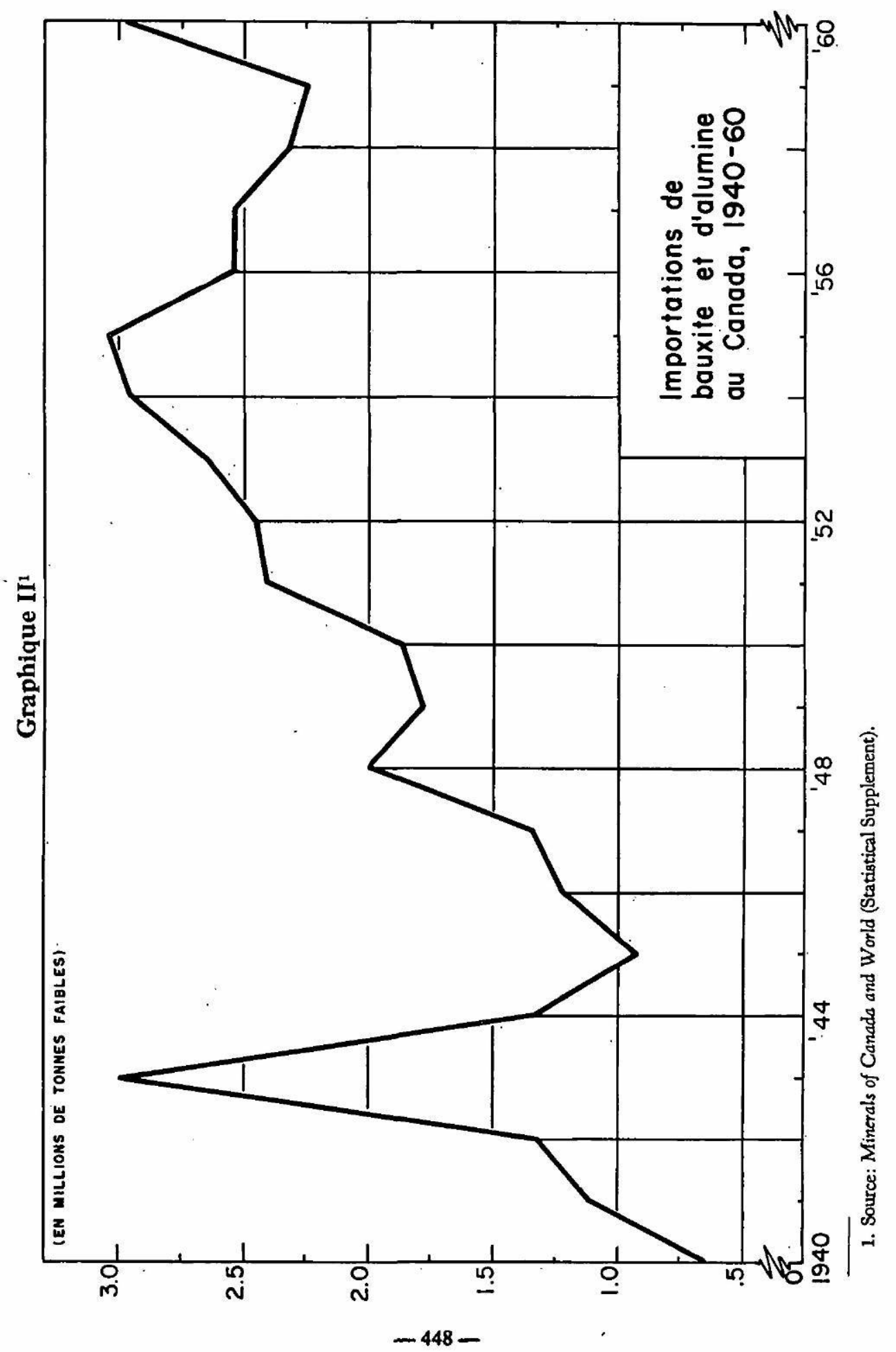


tonnes à Mackenzie (60 millions de dollars). Sur une production totale d'environ deux millions de tonnes, les quatre cinquièmes sont destinés au Canada; le reste va aux Etats-Unis et en Europe.

En Jamaique, la société Alumina Jamaica, autre filiale de l'Alcan, possède non seulement des usines de bauxite, mais aussi deux usines de traitement, celle de Kirkvine (540,000 t.) bâtie en 1957, et celle d'Ewarton $(28,000$ t.) inaugurée en 1959. Cette île des Antilles renferme les plus fortes réserves de bauxite en Amérique: 550 millions de tonnes connues, 450 millions de tonnes possibles. La majeure partie de sa production (entre 5 et 6 millions de tonnes) s'achemine encore à l'état brut vers les Etats-Unis, mais la part exportée sous forme d'alumine, destinée au Canada, est croissante.

Surinam (Guyane néerlandaise) fournit aussi une part de la bauxite vendue au Canada, soit de 300,000 à 350,000 tonnes. Ce territoire a des réserves de 400 millions de tonnes connues et possibles. L'exploitation s'y fait par une filiale d'Alcoa, la Surinam Aluminum Co. (Suralco), qui extrait environ trois millions de tonnes par an, vendues aux Etats-Unis, sauf le dixième destiné au Canada. Suralco y bâtira éventuellement une usine de traitement, une usine d'électrolyse et les centrales hydro-électriques nécessaires.

Depuis quelques années, le Canada importe aussi de la bauxite de Guinée, en Afrique. L'Alcan s'est intéressée aux riches gisements de ce pays (600 millions de tonnes en réserves connues, 2,400 millions possibles) par sa filiale française, Bauxites du Midi. Nos importations furent de 265,000 tonnes en 1959, et de 500,000 en 1960. La société projetait même d'y construire une usine de traitement de 240,000 tonnes à Boké, mais le projet fut abandonné en octobre 1961. Les administrateurs de ce pays, récemment émancipé, seront-ils plus conciliants vis-à-vis de l'autre société, Fria, qui désire, elle aussi, établir une usine de traitement dans la région de Bodé-Konkouré? Enfin, il nous vient de faibles quantités de bauxite de la France méditerranéenne, extraites par deux filiales de l'Alcan. Un nouveau fournisseur est apparu en 1960: l'Australie, où des gisements fort abondants ( 600 millions de tonnes) viennent d'être explorés dans la péninsule du Cap York, au Queensland. Toutefois, la production actuelle provient du gisement de Bell-Bay, exploité en Tasmanie par un monopole d'Etat. 


\section{L'ACTUALITÉ ÉCONOMIQUE}

La majeure partie de la bauxite importée par le Canada nous arrive évidemment par bateau, comme le montrent la carte I et le tableau VII. C'est ainsi qu'en 1959, sur un volume total de $2,257,470$ tonnes figurant dans les données du commerce extérieur, il en a été déchargé aux ports canadiens un volume de 2,085,256 tonnes. Les données de 1960 laissent voir un accroissement sensible: sur près de 3 millions de tonnes importées, environ 2,800,000 tonnes le furent par eau. La différence entre les importations totales et les

\section{Tableau VII}

\section{Le commerce par eau de la bauxite et de l'alumine}

(en tonnes faibles)

\section{A) Cargaisons déchargées}

\begin{tabular}{|c|c|c|c|c|c|c|c|c|}
\hline \multirow{3}{*}{ En provenance de } & \multicolumn{4}{|c|}{1959} & \multicolumn{4}{|c|}{1960} \\
\hline & \multicolumn{4}{|c|}{ aux ports canadiens } & \multicolumn{4}{|c|}{ aux ports canadiens } \\
\hline & $\begin{array}{l}\text { du St- } \\
\text { Laurent }\end{array}$ & $\begin{array}{c}\text { des } \\
\text { Grands } \\
\text { Lacs }\end{array}$ & $\begin{array}{l}\text { du } \\
\text { Paci- } \\
\text { fique }\end{array}$ & Total & $\begin{array}{l}\text { du St- } \\
\text { Laurent }\end{array}$ & $\underset{\substack{\text { des } \\
\text { Lacs }}}{\text { Gands }}$ & $\begin{array}{l}\text { du } \\
\text { Paci- } \\
\text { fique }\end{array}$ & Total \\
\hline 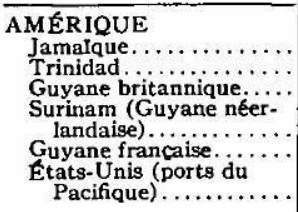 & $\begin{array}{r}630 \\
1,092,768 \\
220,048 \\
107,158 \\
97,785 \\
-\end{array}$ & $\begin{array}{l}9, \overline{231} \\
6,933 \\
7,484 \\
- \\
-\end{array}$ & $\begin{array}{c}318,962 \\
- \\
= \\
61\end{array}$ & \begin{tabular}{|r|}
319,592 \\
$1,101,999$ \\
226,981 \\
114,642 \\
97,785 \\
61 \\
\end{tabular} & $\begin{array}{r}37,352 \\
1,061,176 \\
544,789 \\
191,025 \\
24,231 \\
-\end{array}$ & $\begin{array}{c}\overline{-} \\
28,762 \\
35,978 \\
- \\
-\end{array}$ & $\begin{array}{c}380,408 \\
= \\
= \\
66\end{array}$ & $\begin{array}{r}417,760 \\
1,081,176 \\
573,551 \\
227,003 \\
24,231 \\
66 \\
\end{array}$ \\
\hline Total de l'A merique... & $1,518,389$ & $\widehat{23,648}$ & 319,023 & $1,861,060$ & $\overline{1,858,573}$ & 64,740 & 380,474 & $\overline{2,303,787}$ \\
\hline $\begin{array}{l}\text { AFRIQUE } \\
\text { Guinee (ex. A.O.F.)...... } \\
\text { Union Sud-Africaine.... }\end{array}$ & $\begin{array}{r}178,318 \\
27,112 \\
\end{array}$ & 二 & $=$ & $\begin{array}{r}178,318 \\
27,112\end{array}$ & 475,006 & $\overrightarrow{-}$ & 二 & $\stackrel{475,096}{-}$ \\
\hline Total de l'Afrique..... & 205,430 & & & 205,430 & 475,096 & & & $\overline{475,096}$ \\
\hline $\begin{array}{l}\text { EUROPE } \\
\text { France (ports de la } \\
\quad \text { Mediterranfe) } \ldots \ldots \ldots \\
\text { Royaume-Uni........... }\end{array}$ & $\begin{array}{r}18,739 \\
27 \\
\end{array}$ & 二 & - & $\begin{array}{r}18,739 \\
27 \\
\end{array}$ & $\begin{array}{r}8,432 \\
21 \\
\end{array}$ & 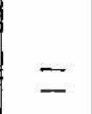 & 二 & $\begin{array}{r}8,432 \\
21 \\
\end{array}$ \\
\hline Total de l'Europe...... & 18,766 & & & 18,766 & 8,453 & & & 8,453 \\
\hline$\underset{\text { Australie }}{\text { OCEANIE }} . \ldots \ldots \ldots$ & - & - & - & - & - & - & 5.803 & 5,803 \\
\hline Total slobal.......... & $1,742,585$ & 23,648 & 319,023 & $2,085,256$ & $2,342,122$ & 64,740 & 386,277 & $2,793,139$ \\
\hline
\end{tabular}

B) Cargaisons chargées

\begin{tabular}{|c|c|c|c|c|c|c|c|c|}
\hline A destination de & & & & & & & & \\
\hline 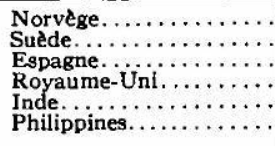 & $\begin{array}{r}54,092 \\
32,175 \\
7,713 \\
-\quad 4 \\
=\end{array}$ & $\begin{array}{l}\text { 二 } \\
\text { Z }\end{array}$ & $\begin{array}{l}\bar{Z} \\
\bar{z}\end{array}$ & $\begin{array}{r}54,092 \\
32,175 \\
7,713 \\
=\quad 4 \\
-\end{array}$ & $\begin{array}{l}1,214 \\
-\quad 61 \\
939 \\
15\end{array}$ & $\begin{array}{l}\bar{Z} \\
\bar{z}\end{array}$ & $\begin{array}{l}= \\
\bar{z}\end{array}$ & $\begin{array}{r}1.214 \\
{ }^{61} \\
938 \\
15\end{array}$ \\
\hline Total global........... & 93.984 & & & 93,984 & 2,229 & & & 2,229 \\
\hline
\end{tabular}


L'ALUMINIUM AU CANADA

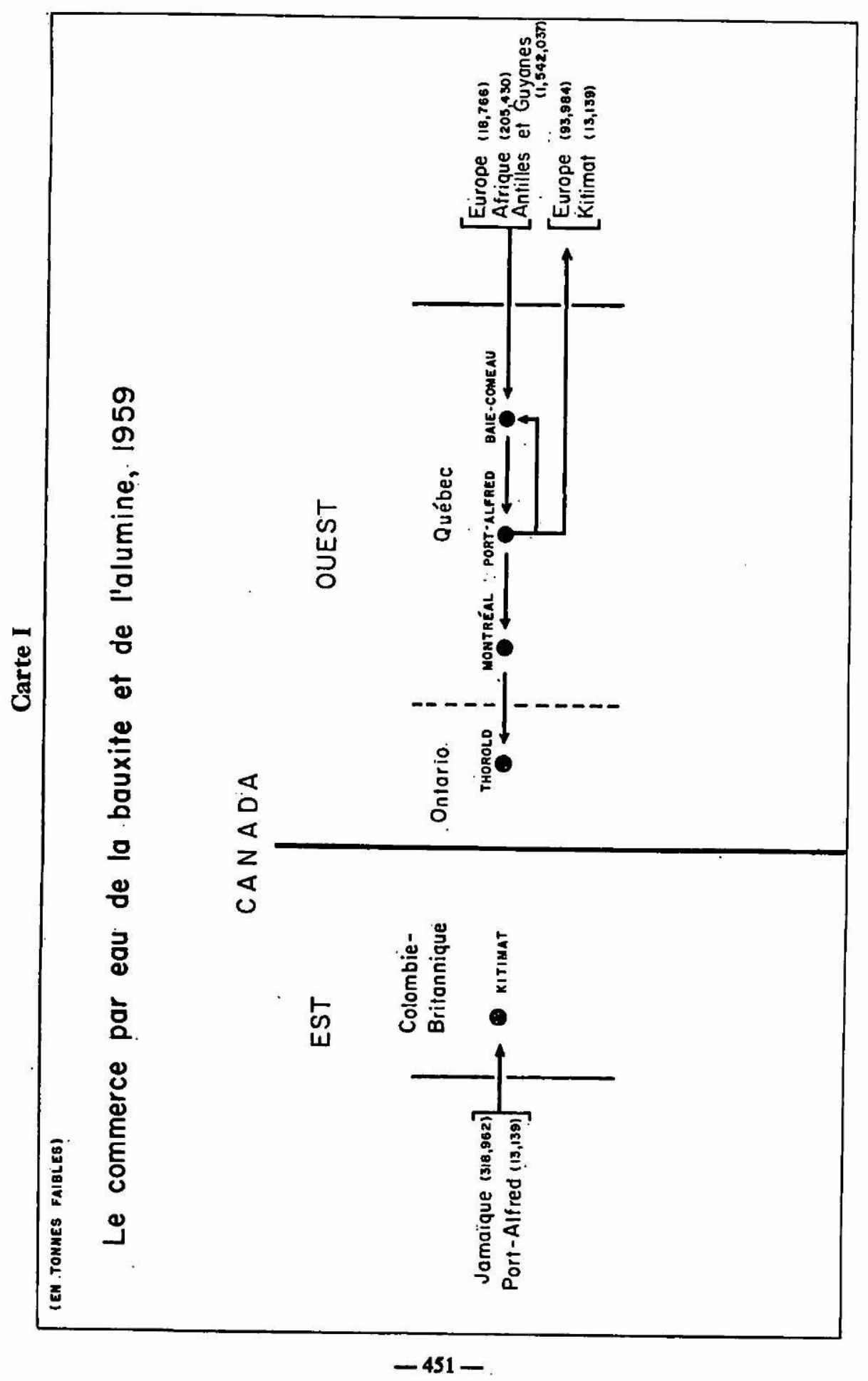


déchargements (ordre de 200,000 t.) s'explique par le fait qu'une centaine de mille tonnes sont livrées par rail (tableaux IX et $\mathrm{X}$ ) via les Etats-Unis et qu'il existe toujours un volume moindre dans les données du trafic par eau que dans celles du commerce total.

Examinons de plus près les courants d'importation par eau de la bauxite et de l'alumine. Quels sont d'abord les pays d'origine? En comparant les tableaux VI et VII, on observe certaines différences. C'est à Trinidad, par exemple, qu'on fait les plus forts chargements, et cette île antillaise n'est pas un fournisseur selon les données du tableau VI, pas plus que la Guyane française. Il s'agit de lieux de transbordement du minerai venu, dans le premier cas, de la Guyane britannique, dans le second, de Surinam. En 1959, il manque environ 72,000 tonnes et en 1960, 150,000 tonnes entre le volume reçu par eau des Antilles et celui qui a été réellement exporté par ces pays. Il en sera de même pour l'Afrique et l'Europe. Cela s'explique de diverses manières. La rubrique "cargaison générale» peut renfermer de ces marchandises dans les données du transport maritime, alors qu'une telle rubrique n'existe pas dans celles du commerce extérieur. La France, par exemple, nous a vendu près de 50,000 tonnes en 1959, alors que moins de 20,000 tonnes seulement figurent aux expéditions par eau. Toutefois, les expéditions par eau de l'Union Sud-Africaine (27,112 tonnes en 1959) s'expliquent moins facilement.

Où aboutissent ces cargaisons? La plus large part remonte le fleuve Saint-Laurent pour être livrée à Port-Alfred (tableau VIII), qui a reçu 1,714,860 tonnes en 1959 , et $2,276,278$ tonnes en 1960 , à Baie-Comeau (18,739 tonnes en 1959 , et 56,805 tonnes en 1960), à Montréal (assez peu), et remonte même la voie maritime jusqu'à Thorold en Ontario, qui a reçu 23,648 tonnes en 1959 et 64,740 tonnes en 1960. Kitimat, sur le littoral du Pacifique, a reçu, sous forme d'alumine, 319,000 tonnes de la Jamaique en 1959, et 386,300 tonnes en 1960. L'examen des statistiques maritimes révè lent en outre, chose inaperçue dans celles du commerce extérieur, un mouvement de transit qui se décompose en plusieurs parties. En 1959, Port-Alfred a expédié près de 94,000 tonnes vers trois pays européens: Norvège, Suède et Espagne. En 1960, ce courant se contracte à 2,229 tonnes dont la moitié vers la Norvège et un peu vers l'Inde. En 1959, il se fit plusieurs mouvements de cabotage. 


\section{L'ALUMINIUM AU CANADA}

Port-Alfred a expédié vers d'autres ports canadiens près de 135,000 tonnes dont 122,230 à Baie-Comeau, portant ainsi l'approvisionnement total de ce dernier port à 141,000 tonnes, volume plus compatible avec les besoins de son usine d'électrolyse que les quelque 19,000 tonnes en provenance d'outre-mer. Kitimat a reçu, pour sa part, 13,139 tonnes d'un port canadien qui ne peut être autre que Port-Alfred via Panama. La notion de cabotage prend ici des proportions inattendues. Les données du cabotage de 1960

\section{Tableau VIII}

\section{Commerce de la bauxite et de l'alumine par eau aux ports canadiens, $1959^{1}$}

(en tonnes faibles)

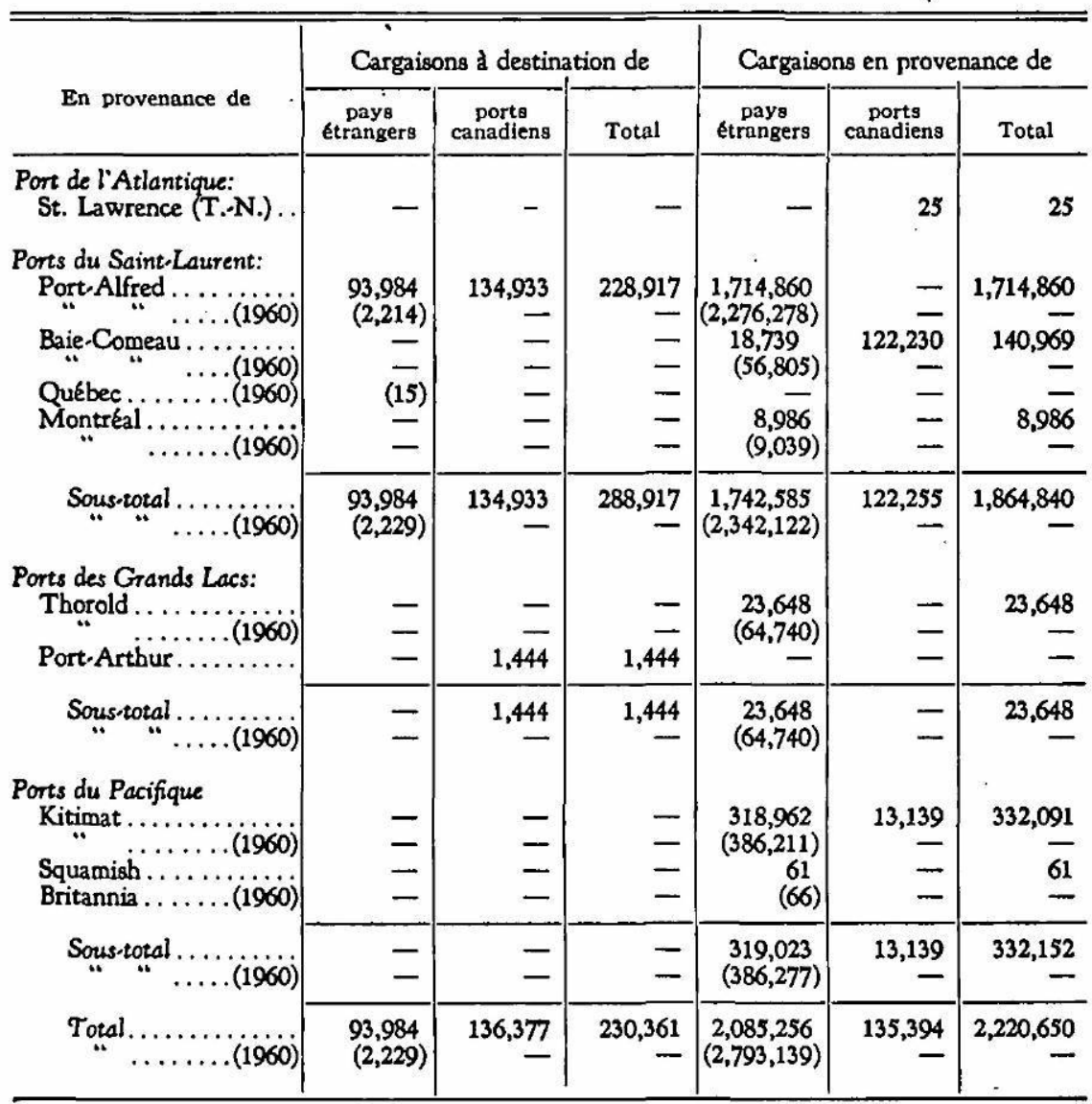

1. Certaines donnés pour 1960 sont indiquées entre parenthèses. 


\section{L'ACTUALITE ECONOMIQUE}

Tableau IX

Volume de l'aluminium transporté par rail au Canada, 1959

(en milliers de tonnes faibles)

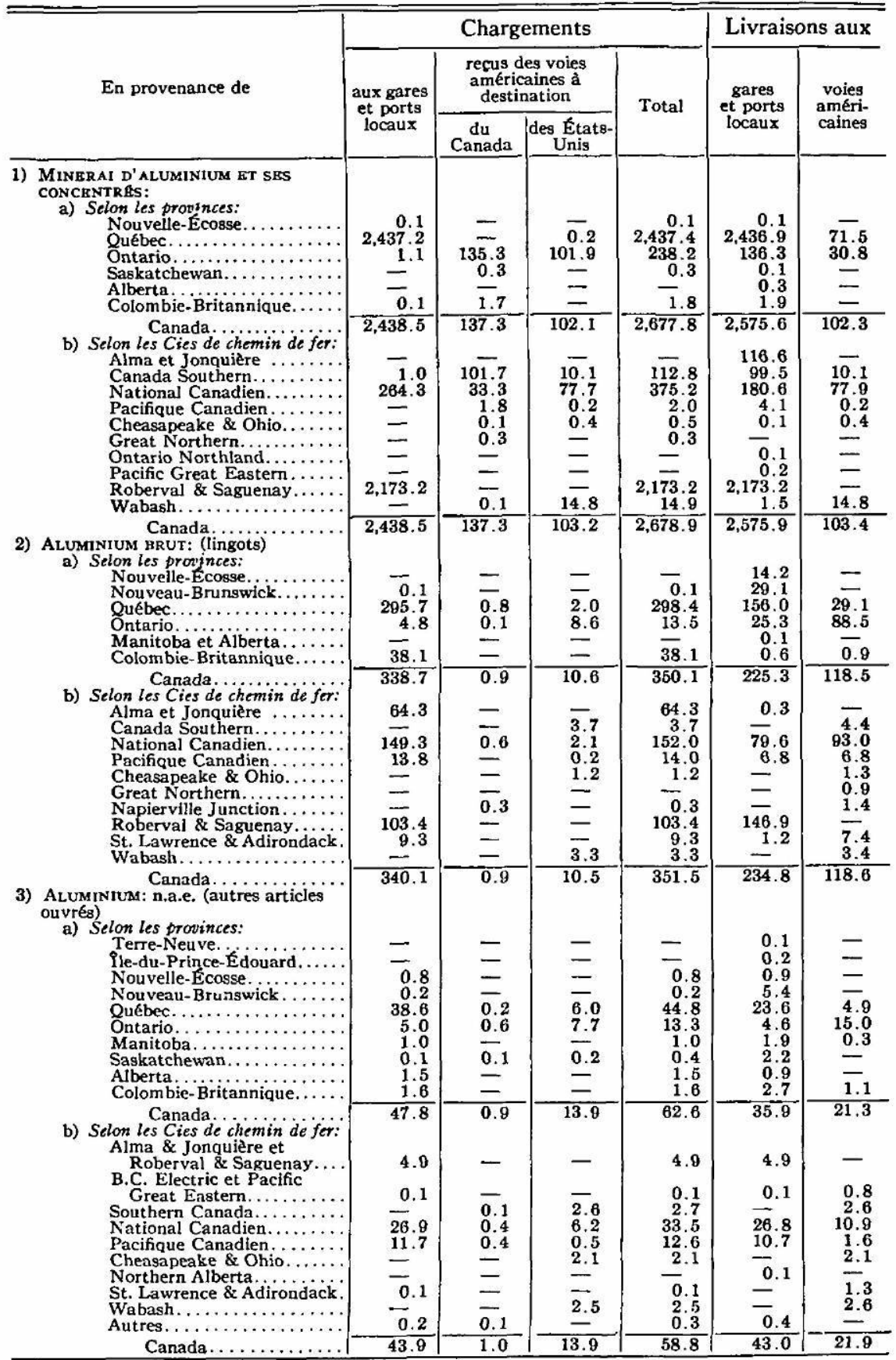


n'étant pas encore publiées au moment où nous écrivons, il nous est impossible d'en discuter.

Le trafic ferroviaire de la bauxite et autres minerais d'aluminium, à l'intérieur du Canada, s'élève à un volume considérable, oscillant entre 2.6 et 2.8 millions de tonnes (tableaux IX et X). Toutefois, il s'effectue en majeure partie sur de faibles distances. Le plus gros volume des chargements sur rail se fait aux quais de Port-Alfred pour être livré par la ligne du Roberval \& Saguenay aux usines d'Arvida. Une partie de la bauxite transformée en alumine retourne sans doute à Port-Alfred, où on l'embarque à destination soit de Baie-Comeau, de Kitimat ou même des pays d'outre-mer mentionnés plus haut. Mais, une autre partie se dirige vers d'autres usines d'électrolyse, celle de l'Isle-Maligne au Saguenay, où les wagons de l'Alma $E^{2}$ Jonquières livrèrent 116,600 tonnes en 1959, et plus de 200,000 tonnes en 1960, puis vers celle de Shawinigan, qui ne reçoit aucun minerai du port de Trois-Rivières, comme on pourrait s'y attendre, enfin peut-être même vers celle de Beauharnois, car les 9,000 tonnes livrées par eau à Montréal sont destinées à une usine chimique de Valleyfield (cette précision nous est apportée par les autorités du port de Montréal).

D'autres courants par rail existent en Ontario. Cette province a reçu des voies ferrées américaines 238,200 tonnes en 1959, et un peu moins en 1960. Mais elle ne garde pour ses usines que la moitié de ce volume environ, soit 136,300 tonnes en 1959 , et 120,000 tonnes, en 1960. Le reste, une centaine de mille tonnes, est en transit en direction des Etats-Unis; cependant, chose curieuse, les deux tiers passent sur le territoire du Québec, vraisemblablement sur les voies du National Canadien en direction de Massena, dans l'Etat de New-York, qui possède deux usines importantes d'électrolyse.

On ne connaît guère le transport du minerai par camion. Peutêtre en fait-on en hiver entre Arvida et Baie-Comeau, privé d'autres moyens de transport. Tout ce que nous avons pu savoir, c'est que les 9,000 tonnes destinées à Valleyfield y sont transportées par camion, à partir du port de Montréal.

Il n'est guère possible non plus de suivre les courants commerciaux des autres matières premières utilisées dans l'industrie de l'aluminium. Le principal de ces produits est la fluorine naturelle 


\section{L'ACTUALITÉ ECONOMIQUE}

\section{Tableau X}

Volume de l'aluminium transporté par rail au Canada, 1960 (en milliers de tonnes faibles)

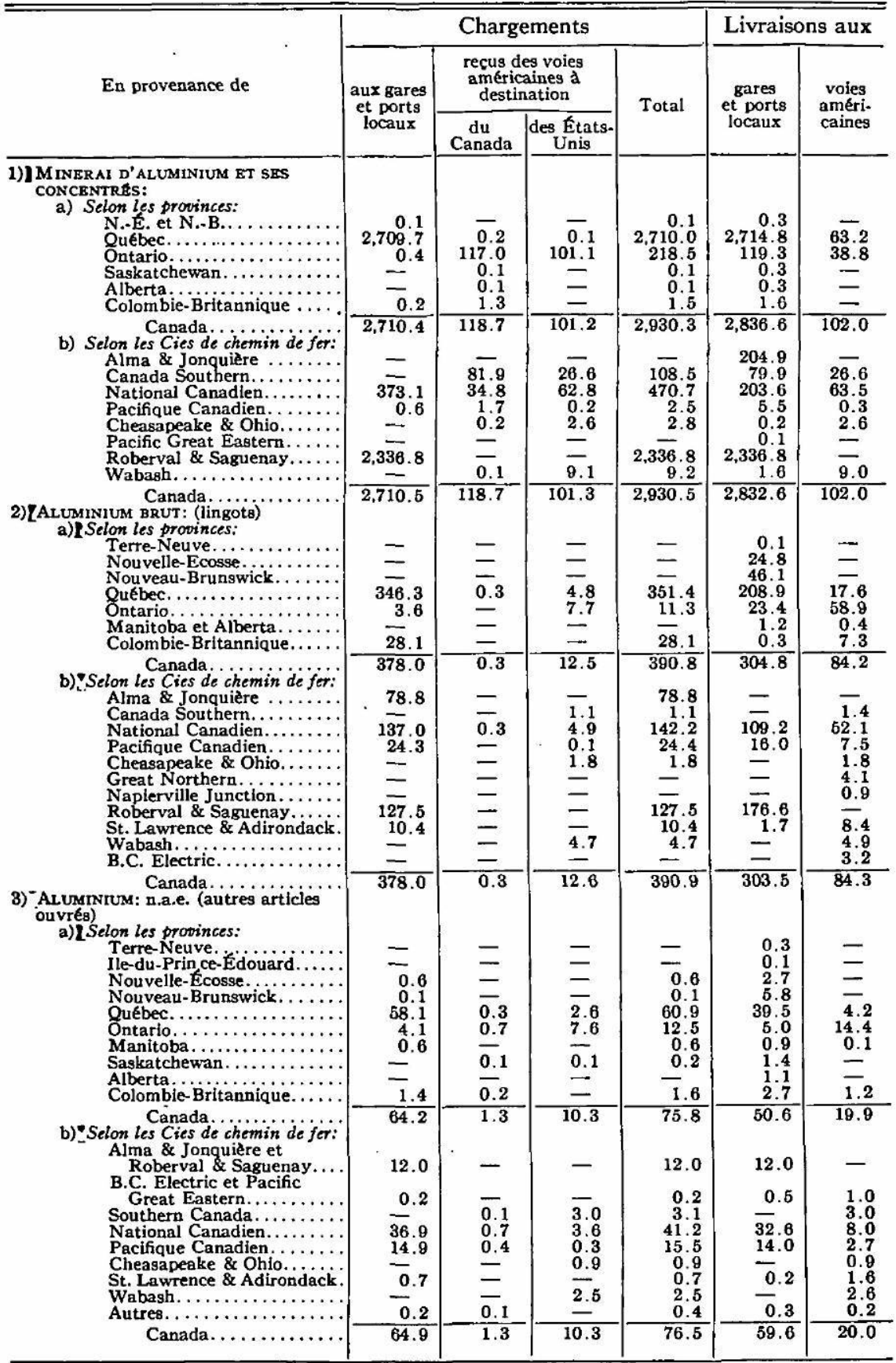


ou synthétique. La première vient d'un gisement unique au monde, celui d'Ivigtut, au Groënland. Le Canada l'importe du Danemark: environ 6,000 tonnes en 1959 , et 8,300 tonnes en 1960 , dont près de la moitié, durant cette dernière année, est venue d'Italie. Quant à la fluorine synthétique, elle se fabrique à partir du spath fluor dont il existe un gisement à St. Lawrence, au sud-est de TerreNeuve, produisant environ 60,000 tonnes par année. Il semble cependant que la société Newfoundland Fluorspar Ltd., filiale de l'Alcan, ait beaucoup ralenti ses opérations, et que les usagers canadiens s'approvisionnent désormais au Mexique, qui a doublé ses ventes au Canada depuis 1957.

La seule manière d'estimer les courants commerciaux qui se rapportent à la fluorine naturelle et synthétique est de scruter la rubrique intitulée «autres minerais bruts non métalliques» dans le Shipping Report, rubrique trop vague, sans doute, car elle renferme d'autres matières non identifiables. En 1959, les ports du SaintLaurent et de l'Atlantique ont déchargé 37,176 tonnes de tous ces minéraux en provenance de l'étranger, les principaux fournisseurs étant le Mexique, avec 22,240 tonnes à lui seul, et le Danemark avec près de 6,000 tonnes. En 1960, ce mouvement s'est grossi à près de 60,000 tonnes, dont 45,000 tonnes venues du Mexique, 6,400 d'Italie, 4,000 tonnes des Etats-Unis et seulement 2,300 tonnes du Danemark. Chose curieuse, Port-Alfred n'a rien reçu directement de l'étranger en 1959, tandis qu'il en a déchargé 23,500 tonnes en 1960. Son approvisionnement de 1959, Port-Alfred l'a fait au cabotage, en déchargeant 60,000 tonnes en provenance soit de St. Lawrence (T.N.), qui a expédié 32,000 tonnes au cabotage, soit de Montréal, qui a reçu de l'étranger 24,000 tonnes, ou d'autres ports du St-Laurent et de l'Atlantique.

Kitimat, lui non plus, n'a rien reçu directement de l'étranger en 1959 et en 1960. Pourtant, son port a déchargé 16,400 tonnes au cabotage en 1959, en provenance des ports de l'Est, probable, ment de Port-Alfred qui a expédié 8,300 tonnes et, chose surprenante, de Port-Cartier, qui en a chargé 4,600 tonnes. Enfin, BaieComeau a reçu de l'étranger 6,000 tonnes en 1959 et 5,000 en 1960. Il faudrait connaître les données du cabotage de 1960 pour être mieux renseigné sur ce sujet. 
L'ACTUALITÉ ECONOMIQUE

Graphique III

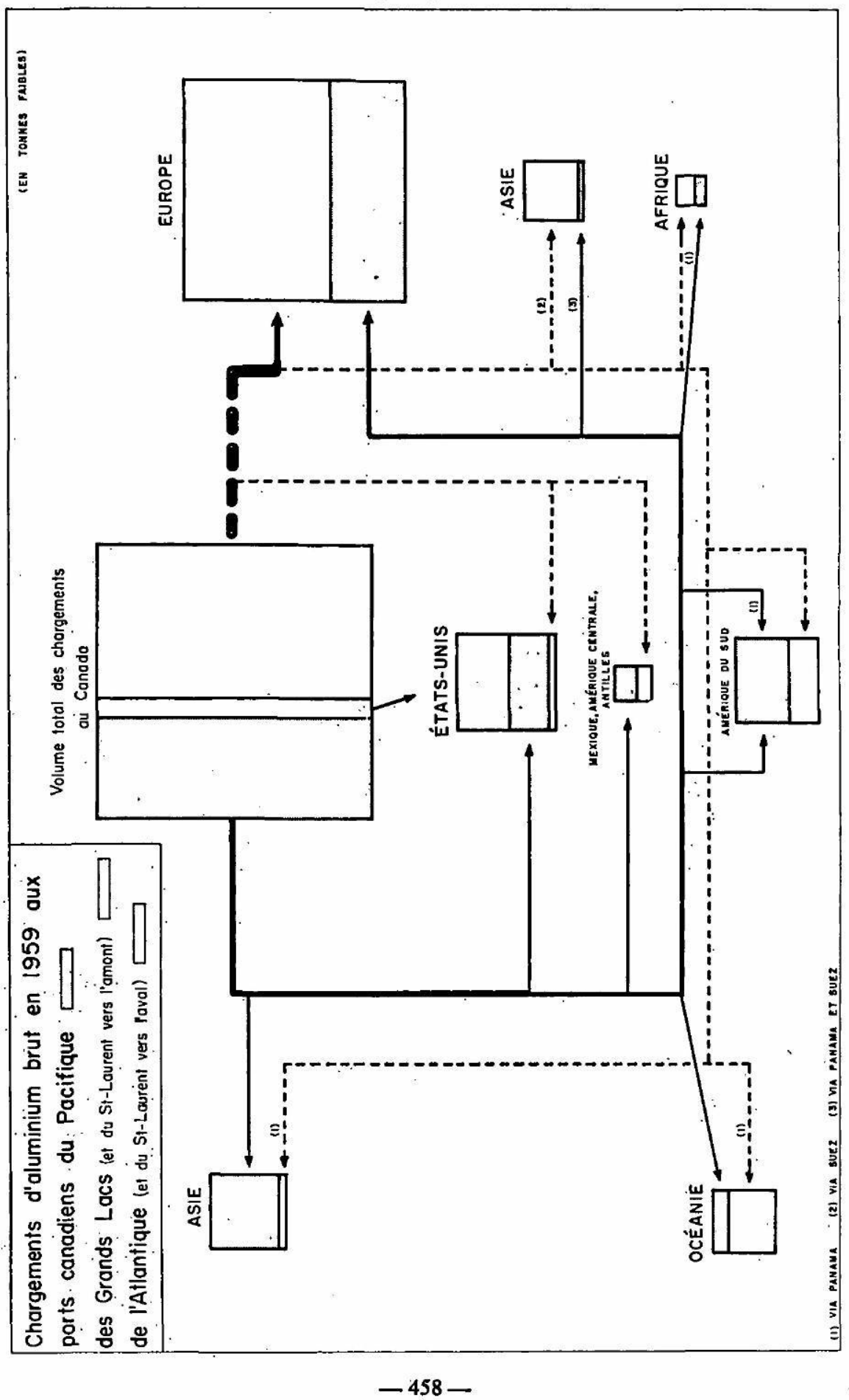


Le Canada exporte la majeure partie de l'aluminium qu'il fabrique (voir le graphique I). En 1959, il a vendu à l'étranger pour 230.9 millions de dollars sous forme d'aluminium brut et semi-ouvré; soit un volume de 546,800 tonnes, et encore plus en 1960, avec 610,110 tonnes d'une valeur de 268.3 millions (voir tableau II). Il est évident que le gros de ce commerce se fait par eau, sauf les expéditions terrestres vers les Etats-Unis. Les données du commerce maritime indiquent, en effet, un volume global de 342,422 tonnes chargées aux ports canadiens à destination des pays étrangers en 1959, et un volume de 390,770 tonnes en 1960. Or, ces volumes sont trop faibles de 200,000 à 220,000 tonnes chacun en regard du commerce global. Ceci, croyons-nous, s'explique par la part qui, expédiée par eau, tombe sous la rubrique vague de *cargaisons générales».

Examinons d'abord les courants d'exportations par eau. Les meilleurs clients de l'aluminium canadien se trouvent en Europe (graphiques III et IV). Le Canada a exporté 273,300 tonnes en 1959, et 346,600 tonnes en 1960, sur le continent européen. De ce volume, on ne peut suivre la trace par les courants maritimes que de 220,462 tonnes en 1959, et 248,186 tonnes en 1960. Les deux tiers, en 1959, s'acheminent directement par le Saint-Laurent et l'océan Atlantique, le reste s'y rend en faisant le détour du canal de Panama; en 1960, ce sont les trois quarts qui prennent la première route.

Le Royaume-Uni est le premier client européen du Canada. A lui seul, il prend 60 p.c. du volume en 1959, et encore plus de la moitié en 1960. Toutefois, notre pays a des concurrents sur ce marché: les Etats-Unis, dont les ventes sont passées du tiers des ventes canadiennes en 1959 aux deux tiers en 1960, puis la Norvège et même l'U.R.S.S., toutefois négligeable en 1960. Le Canada n'en demeure pas moins le premier fournisseur du Royaume-Uni avec plus de la moitié, en 1959 et 1960, de l'aluminium qu'importe ce pays. Ajoutons que ce dernier ne produit guère plus du dixième de laluminium de première fusion dont il a besoin. Notre second client européen est l'Allemagne de l'Ouest, dont le volume des importations a doublé entre 1959 et 1960. Le Canada fut son principal fournisseur en 1959, mais avec le tiers seulement de ce 
L'ACTUALITE ECONOMIQUE

Graphique IV

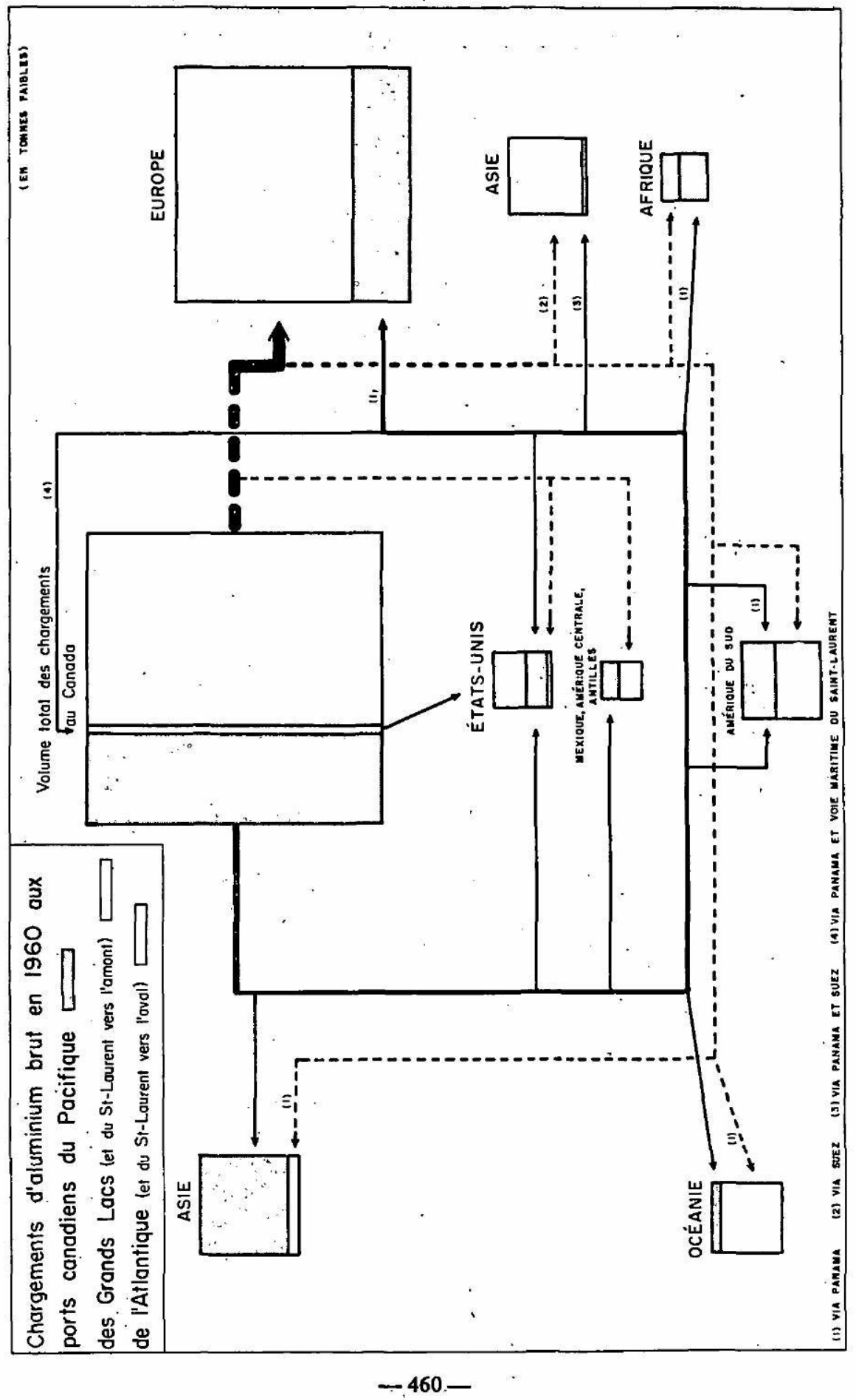


qu'il achète à l'étranger, en 1959. La Norvège, les Etats-Unis, l'Autriche, la France et la Suisse concurrençaient alors le Canada sur le marché allemand, et en 1960 le Canada s'est vu ravir la première place par les Etats-Unis, qui ont quintuplé leurs exportations vers ce pays.

L'Allemagne de l'Ouest est le pays d'Europe qui possède la plus puissante industrie de l'aluminium après la France. Interdite à la fin de la seconde guerre mondiale, la fabrication de l'aluminium brute n'a pu reprendre qu'après 1950. En effet, la production est passée de moins de 30,000 tonnes métriques cette année-là à près de 170,000 tonnes dix ans plus tard. Toutefois, la consommation du pays est presque deux fois plus forte. On l'estime à 300,000 tonnes en 1960. La principale entreprise, Vereinigte Aluminum Werke A.G., a une capacité de 130,000 tonnes dans ses trois usines d'électrolyse sur les rivières Inn, Lippe et Erft. L'autre, Aluminum Hütte, peut fabriquer 50,000 tonnes près de Rheinfelden, sur la frontière suisse.

La France, qui était notre troisième client en 1959, a réduit de moitié ses importations du Canada en 1960. Nous étions alors son premier fournisseur, suivi de près par le Cameroun. Or, en 1960, le Cameroun a doublé les ventes du Canada sur ce marché et les Etats-Unis ont surpassé le Canada d'un tiers.

La France, avons-nous dit plus haut, arrive en tête des producteurs européens d'aluminium. Ce pays fut un des premiers vers la fin du XIX ${ }^{e}$ siècle à fabriquer ce métal nouveau, grâce à ses gisements de bauxite (mot issu du village de Baux en Provence) et à son énergie hydróélectrique dans les Alpes. Ses progrès furent rapides durant l'après-guerre, la production ayant quadruplé durant les dix dernières années, soit de 60,710 tonnes en 1950 à 235,200 tonnes en 1960. La capacité des usines atteint 300,000 tonnes à la fin de 1961. Deux sociétés se partagent les 12 fabriques en Métropole: 9 totalisant 246,000 tonnes appartiennent au groupe de Péchiney, 3 totalisant 54,500 tonnes appartiennent au groupe d'Ugine. La plupart sont de modestes usines vues à l'échelle canadienne, à cause des ressources limitées en énergie hydraulique tirée des Alpes et des Pyrénées. La plus importante usine d'électrolyse de Péchiney, par exemple, celle de Saint-Jean de Maurienne, 
en Savoie, a une capacité de 73,000 tonnes, donc égale à celle de Shawinigan. Toutefois, l'usage du gaz de Lacq vient de permettre le montage de deux usines nouvelles au pied des Pyrénées, l'une à Noguères (Péchiney) qui atteindra 90,000 tonnes en 1962, l'autre de 28,000 tonnes à Lannemezan (Ugine). Les importations françaises d'aluminium en lingots ne sont donc que temporaires et considérées comme une ressource d'appoint.

L'Italie a remplacé le pays précédent comme troisième client européen du Canada, en 1960, ayant doublé ses importations en regard de 1959, année où le Canada lui a fourni le tiers de ses besoins, suivi de près par l'Autriche et la France. En 1960, la Norvège a devancé le Canada sur le marché italien et les EtatsUnis surpassent la France et l'Autriche. L'Italie importe presque la moitié de l'aluminium brut dont ont besoin ses industries de transformation; cependant, le producteur principal, Montecatini, (60 p.c. du pays) se propose de construire, en Sardaigne, une usine de 100,000 tonnes, deux fois plus importante que celles dont il dispose présentement dans la péninsule.

La Belgique fut le quatrième client d'aluminium du Canada en 1960, en accroissant ses achats d'un tiers en regard de 1959. Mais la France y exporte trois fois plus d'aluminium que le Canada en 1959 et en 1960.

Vient ensuite la Suisse, qui achète un peu moins en 1960 qu'en 1959, mais le Canada demeure son principal fournisseur. En Suisse, comme au Canada, l'industrie de l'aluminium est un des meilleurs exemples de diversification géographique ${ }^{1}$. La principale entreprise, l'A.I.A.G. (Aluminium Industrie Aktien Gesellschaft), intéresse une bonne douzaine de pays. Au stade de la production brute seulement, ses usines d'électrolyse sont: en Suisse, à Chippis (35,200 t.); en Allemagne, à Rheinfelden (50,000 t.); en Italie, à Porto Marghera $(27,000$ t.); en Norvège, où elle participe au tiers de la production de Mosjoen (8,800 t.); en Autriche, à Lend (7,000 t.). Donc, sur une production totale de 128,000 tonnes, moins du tiers vient du territoire national.

1. G.A. Baudart, L'A.I.A.G.-Suisse, Revue de l'Aluminium (Paris), 38 année, no 289, juillet-août 1961, pp. $867-869$. 
La Suède achète peu du Canada. C'est évidemment sa voisine scandinave, la Norvège, qui lui fournit l'aluminium qu'elle importe. Quant à l'Espagne, qui a doublé ses achats entre 1959 et 1960 , elle les fait presque totalement au Canada. Un assez gros tonnage fgure aux statistiques maritimes vers les Pays-Bas: 21,600 tonnes en 1959, deux fois plus en 1960. Mais le pays n'en garde pour lui que le dixième, car ses ports, Rotterdam surtout, font du commerce de transit vers l'Allemagne.

Après ceux du continent européen, ce sont nos clients d'Amérique qui achètent le plus d'aluminium canadien. Mais si nos ventes à l'Europe se sont accrues en 1959 et 1960, elles ont, au contraire, diminué en Amérique: le volume s'est réduit d'un quart, de 205,615 tonnes à 149,455 tonnes. Or, ce sont les Etats-Unis qui ont singulièrement réduit leurs achats au Canada, passant de 184,820 à 115,355 tonnes. L'Amérique du Sud, au contraire, ainsi que les autres pays d'Amérique les ont augmenté d'un bon tiers.

Les Etats-Unis, dont la production est croissante, ainsi que nous l'avons vu précédemment, n'éprouvent plus le besoin d'im. porter autant d'aluminium qu'auparavant. En 1953, par exemple, ils avaient acheté à l'étranger 301,000 tonnes d'aluminium brut, dont 224,000 tonnes du Canada. En 1959, ils n'ont importé que 240,000 tonnes des mêmes produits dont 166,400 tonnes du Canada. La baisse est encore plus marquée en 1960, avec un volume estimé à 140,000 tonnes, dont moins de 100,000 tonnes du Canada. Non seulement les ventes canadiennes furent réduites de moitié sur ce marché, mais le Canada y rencontre plusieurs concurrents, tels que la Norvège depuis longtemps, et des nouveaux venus comme la France, le Cameroun et l'Italie. En 1959, les Etats-Unis ont acheté pour 152.1 millions de dollars d'aluminium à l'étranger, mais guère plus de la moitié au Canada, soit pour une valeur de 81.5 millions. Durant les neuf premiers mois de 1960, la valeur de leurs importations ne fut toutefois que de 80 millions de dollars. Le Canada reste quand même le premier 'fournisseur de son voisin avec 41.8 millions, mais l'Europe occidentale nous suit d'assez près avec 34 millions.

En face d'un tel déclin, quasi alarmant, l'Alcan a fait présenter un mémoire devant la Commission américaine des Tarifs douaniers afin de faire réduire le plus possible ou même de faire supprimer 
les droits d'un cent et quart la livre qui sont imposés sur l'aluminium brut à l'entrée des Etats-Unis'.

Une faible part de l'aluminium canadien exporté aux EtatsUnis s'achemine par eau, soit environ 50,000 tonnes en 1959, et 20,000 tonnes en 1960 (tableau XI). Les deux courants principaux s'orientent, en 1959, l'un par la voie maritime du Saint-Laurent à destination des ports américains des Grands-Lacs, l'autre longe le littoral de l'océan Pacifique (graphique III). En 1960, le phénomène s'est réduit des deux tiers, mais on aperçoit (graphique IV) un singulier chargement de 2,151 tonnes, en provenance de Kitimat, qui passe par le canal de Panama et remonte le Saint-Laurent pour aboutir aux ports lacustres. Les principales livraisons d'aluminium aux Etats-Unis se font surtout par rail et sans doute aussi par la route, ainsi que nous le verrons plus loin.

Les autres pays d'Amérique achètent de plus en plus d'aluminium au Canada, soit une vingtaine de mille tonnes en 1959, 35,000 tonnes en 1960. Ce n'est certes pas énorme en comparaison des pays précédents, mais, comme la plupart de ces pays d'Amérique latine sont en voie d'expansion, il convient d'en examiner les besoins et de voir si le Canada ne pourrait pas leur en vendre davantage. Prenons, en exemple, les quatre principaux clients du Canada. Le Brésil est au premier rang. Il ne possède encore qu'une usine d'électrolyse, celle d'Ouro Preto, au Minas Geraes, filiale d'Aluminium Ltd, dont la capacité vient d'être portée à 18,000 tonnes. Le pays importe de 10,000 à 12,000 tonnes, fournies aux deux tiers par le Canada, son plus proche concurrent étant la Norvège. L'Argentine, qui n'a aucune industrie d'aluminium brut, importe aussi une dizaine de mille tonnes, dont la moitié du Canada. Nos concurrents sur ce marché en 1959 étaient la France, l'Autriche et l'Italie. En 1960, ce fut les Etats-Unis qui ont vendu à l'Argentine un volume presque égal à celui du Canada. Le Mexique, privé lui aussi de ce genre d'industrie, a doublé ses importations entre 1959 et 1960 , de 6,400 tonnes à 12,000 tonnes. Le Canada lui en vend plus de la moitié, suivi par les Etats-Unis. Le Venezuela, pour sa part, requiert une dizaine de mille tonnes, mais notre pays

1. Memorandum of Aluminium Sales Inc., New York, N.Y. in support of maximum possible reduction in existing tariff duty, présenté le 22 decembre 1960, 27 pages. 


\section{L'ALUMINIUM AU CANADA}

Tableau XI

\section{Le commerce par eau de l'aluminium}

(en tonnes faibles)

\section{A) Cargaisons chargées}

\begin{tabular}{|c|c|c|c|c|c|c|c|c|}
\hline \multirow[b]{3}{*}{ À destination de } & \multicolumn{4}{|c|}{1959} & \multicolumn{4}{|c|}{1960} \\
\hline & \multicolumn{4}{|c|}{ aux ports canadiens } & \multicolumn{4}{|c|}{ aux ports canadiens } \\
\hline & $\begin{array}{l}\text { du St- } \\
\text { Laurent } \\
\text { et de } \\
\text { l'Atlan- } \\
\text { tique } \\
\end{array}$ & $\underset{\substack{\text { des } \\
\text { Lacs }}}{ }$ & $\underset{\text { Pacifique }}{\text { du }}$ & Total & $\begin{array}{l}\text { du St- } \\
\text { Laurent } \\
\text { et de } \\
\text { l'Atlan- } \\
\text { tique }\end{array}$ & $\left\{\begin{array}{c}\text { des } \\
\text { Grands } \\
\text { Lacs }\end{array}\right.$ & $\begin{array}{c}\mathrm{du} \\
\text { Pacifique }\end{array}$ & Total \\
\hline 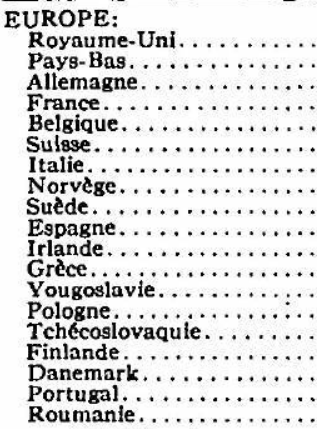 & $\begin{array}{r}76,558 \\
4,728 \\
7,200 \\
15,904 \\
7,694 \\
8,974 \\
7,974 \\
3,354 \\
2,015 \\
2,480 \\
2,507 \\
1,389 \\
3.035 \\
1,228\end{array}$ & $\begin{array}{l}\overline{14} \\
= \\
= \\
= \\
= \\
= \\
= \\
= \\
= \\
=\end{array}$ & $\begin{array}{r}51.263 \\
16.855 \\
4,601 \\
1,654 \\
638 \\
= \\
= \\
= \\
= \\
=\end{array}$ & $\begin{array}{r}127,811 \\
21,592 \\
11,725 \\
17,558 \\
7,694 \\
9,607 \\
7,974 \\
3,354 \\
2,015 \\
2,430 \\
2,507 \\
1,989 \\
3,035 \\
1,228 \\
329 \\
1 \\
203 \\
\end{array}$ & $\begin{array}{r}102,801 \\
11,511 \\
26,818 \\
4,916 \\
8,880 \\
3,339 \\
12,303 \\
6 \\
5,264 \\
4,703 \\
2,409 \\
2,304 \\
11 \\
1,034 \\
945 \\
8 \\
8 \\
81 \\
111 \\
\end{array}$ & $\begin{array}{l}= \\
= \\
= \\
= \\
= \\
= \\
= \\
= \\
=\end{array}$ & $\begin{array}{r}29,866 \\
\text { 二 } \\
\bar{z} \\
\text { 二 } \\
\text { 二 } \\
\text { 二 } \\
\text { 二 } \\
\text { 二 }\end{array}$ & $\begin{array}{r}182,167 \\
42,869 \\
26,818 \\
4,916 \\
8,880 \\
3,339 \\
12,318 \\
6 \\
5,264 \\
4,703 \\
2,409 \\
2,304 \\
11 \\
1,034 \\
945 \\
3 \\
8 \\
81 \\
81 \\
111\end{array}$ \\
\hline Total Europe......... & 145,518 & 38 & 74,906 & $\overline{220.462}$ & $\overline{187,447}$ & - & 60.739 & 248.186 \\
\hline 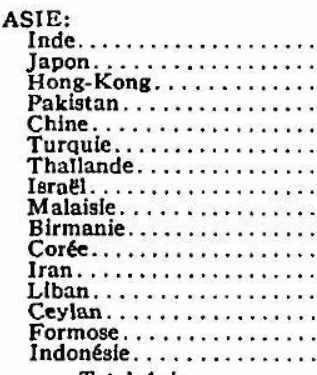 & $\begin{array}{r}12,902 \\
975 \\
1,193 \\
\frac{7}{556} \\
40 \\
271 \\
= \\
\overline{7} \\
\overline{81} \\
2 \\
1\end{array}$ & $\begin{array}{l}= \\
= \\
= \\
= \\
= \\
= \\
= \\
=\end{array}$ & $\begin{array}{r}599 \\
11,026 \\
10,552 \\
1,177 \\
= \\
= \\
251 \\
241 \\
= \\
=\end{array}$ & $\begin{array}{r}13,501 \\
12,001 \\
10,552 \\
2,370 \\
\overline{7} \\
556 \\
40 \\
271 \\
251 \\
241 \\
\frac{7}{31} \\
2 \\
1 \\
\end{array}$ & $\begin{array}{r}16,714 \\
2,914 \\
114 \\
5,751 \\
2,717 \\
740 \\
114 \\
\frac{2}{7} \\
644 \\
27 \\
= \\
\end{array}$ & $\begin{array}{l}= \\
= \\
= \\
= \\
= \\
= \\
=\end{array}$ & $\begin{array}{r}1,445 \\
15,174 \\
16,344 \\
1,417 \\
6,725 \\
\frac{66}{3} \\
\frac{3}{73} \\
= \\
= \\
\end{array}$ & $\begin{array}{r}18,159 \\
18.088 \\
16,458 \\
7,168 \\
6,725 \\
2,717 \\
806 \\
114 \\
5 \\
\overline{5} \\
78 \\
644 \\
27 \\
\end{array}$ \\
\hline Total Asie........... & 15,971 & - & 28,846 & 39.817 & 29,737 & - & $\mathbf{4 1 , 2 4 7}$ & 70,984 \\
\hline $\begin{array}{l}\text { AMERIQUE: } \\
\text { Etats-Unis } \\
\text { (ports de l'Atlantique). } \\
\text { Etats-Unis } \\
\text { (ports des Grands Lacs). } \\
\text { Etats-Unis } \\
\text { (ports du Pacifique). . . . }\end{array}$ & $\begin{array}{r}8,186 \\
22,816\end{array}$ & 171 & 17,100 & $\begin{array}{r}8,186 \\
22,987\end{array}$ & 6,365 & - & 2,151 & 8,616 \\
\hline Total Elats-Unis..... & 26,002 & $\overline{171}$ & 17.100 & 48,273 & 6,589 & - & 7,652 & 14,241 \\
\hline 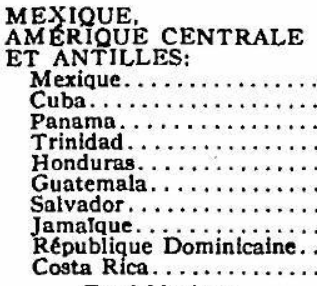 & $\begin{array}{r}1,949 \\
302 \\
102 \\
= \\
=\end{array}$ & $\begin{array}{l}= \\
= \\
= \\
=\end{array}$ & $\begin{array}{r}8.697 \\
= \\
= \\
= \\
=\end{array}$ & $\begin{array}{r}5,646 \\
802 \\
102 \\
- \\
\\
81 \\
18 \\
1 \\
2 \\
\end{array}$ & $\begin{array}{r}8,298 \\
107 \\
415 \\
146 \\
100 \\
36 \\
= \\
\text { 二 } \\
\end{array}$ & $\begin{array}{l}= \\
= \\
= \\
= \\
=\end{array}$ & $\begin{array}{r}\text { 9,166 } \\
= \\
= \\
= \\
=\end{array}$ & $\begin{array}{r}6.464 \\
107 \\
415 \\
146 \\
100 \\
36 \\
= \\
=\end{array}$ \\
\hline $\begin{array}{c}\text { Total Mexique, } \\
\text { Amtrique Centrale } \\
\text { et Antilles......... }\end{array}$ & 2,401 & 4 & 3,697 & 6,102 & 4,102 & & 3,166 & 7,268 \\
\hline
\end{tabular}




\section{L'ACTUALITÉ ÉCONOMIQUE}

\section{Tableau XI (suite)}

\section{Le commerce par eau de l'aluminium}

(en tonnes faibles)

\section{A) Cargaisons chargées}

\begin{tabular}{|c|c|c|c|c|c|c|c|c|}
\hline \multirow[b]{3}{*}{$\hat{A}$ destination de } & \multicolumn{4}{|c|}{1959} & \multicolumn{4}{|c|}{1960} \\
\hline & \multicolumn{4}{|c|}{ aux ports canadiens } & \multicolumn{4}{|c|}{ aux ports canadiens } \\
\hline & $\begin{array}{l}\text { du St- } \\
\text { Laurent } \\
\text { et de } \\
\text { l'Atlan- } \\
\text { tique }\end{array}$ & $\underset{\substack{\text { des } \\
\text { Lacs }}}{\text { Lacs }}$ & $\begin{array}{c}\text { du } \\
\text { Pacifique }\end{array}$ & Total & $\begin{array}{l}\text { du St- } \\
\text { Laurent } \\
\text { et de } \\
\text { l'Atlan- } \\
\text { tique }\end{array}$ & $\begin{array}{c}\text { des } \\
\text { Grands } \\
\text { Lacs }\end{array}$ & \begin{tabular}{|} 
du \\
Pacifique
\end{tabular} & Total \\
\hline 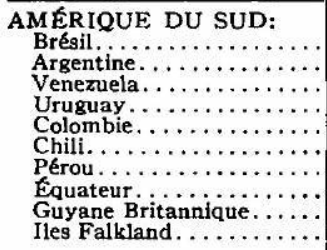 & $\begin{array}{r}5,729 \\
3,345 \\
615 \\
1,123 \\
182 \\
133 \\
66 \\
48 \\
=\end{array}$ & $\begin{array}{l}= \\
= \\
= \\
= \\
=\end{array}$ & $\begin{array}{l}= \\
= \\
= \\
= \\
=\end{array}$ & $\begin{array}{r}5,729 \\
3,345 \\
615 \\
1,123 \\
182 \\
133 \\
66 \\
48 \\
=\end{array}$ & $\begin{array}{r}10,946 \\
8,763 \\
273 \\
987 \\
276 \\
112 \\
199 \\
37 \\
7 \\
4\end{array}$ & $\begin{array}{l}= \\
= \\
= \\
= \\
=\end{array}$ & $\begin{array}{l}\text { = } \\
= \\
= \\
= \\
=\end{array}$ & $\begin{array}{r}11.584 \\
3.768 \\
278 \\
987 \\
276 \\
181 \\
199 \\
197 \\
7 \\
7 \\
4\end{array}$ \\
\hline Total Amerique....... & 11,241 & - & - & 11,241 & 16,604 & - & 707 & 17,811 \\
\hline Total Ambrique du Sud & 39,644 & 175 & 20,797 & 60,616 & 27,295 & - & 11,525 & 38,820 \\
\hline $\begin{array}{l}\text { OCEANIE: } \\
\text { Australie } \ldots \ldots \ldots \ldots \ldots \ldots \\
\text { Nouvelle-Zélande } \ldots \ldots \ldots \ldots\end{array}$ & $\begin{array}{r}11,776 \\
1,137\end{array}$ & $=$ & $\stackrel{4,560}{-}$ & $\begin{array}{r}16,836 \\
1,137\end{array}$ & $\begin{array}{r}16.680 \\
2857\end{array}$ & $=$ & 3,920 & $\begin{array}{r}20,600 \\
2,857\end{array}$ \\
\hline Tolal OcEanie........ & 12,913 & - & 4,660 & 17,478 & 19,587 & - & 3,920 & 23,457 \\
\hline 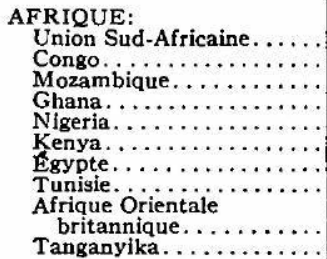 & $\begin{array}{r}2,112 \\
299 \\
30 \\
\frac{6}{29} \\
- \\
4\end{array}$ & $\begin{array}{l}= \\
= \\
= \\
=\end{array}$ & $\begin{array}{r}1,574 \\
= \\
= \\
= \\
=\end{array}$ & $\begin{array}{r}8,686 \\
299 \\
\frac{30}{6} \\
\frac{6}{29} \\
4 \\
\end{array}$ & $\begin{array}{r}2.574 \\
908 \\
273 \\
51 \\
\frac{48}{45} \\
-2\end{array}$ & $\begin{array}{l}= \\
z \\
z \\
z \\
z\end{array}$ & $\begin{array}{r}\text { E } \\
\text { 二 } \\
\text { 二 } \\
= \\
=\end{array}$ & $\begin{array}{r}8.001 \\
908 \\
273 \\
51 \\
43 \\
\frac{45}{45} \\
-2\end{array}$ \\
\hline Total Afrique. ....... & 2,480 & $\sim$ & 1,574 & 4,054 & 8,896 & - & 5,427 & 8,328 \\
\hline Total global. ......... & 216,526 & 213 & 125,683 & 842,422 & 267,912 & - & 122,858 & 889,770 \\
\hline
\end{tabular}

\section{B) Cargaisons déchargées}

\begin{tabular}{|c|c|c|c|c|c|c|c|c|}
\hline EN PROVENANCE DE & & & & & & & & \\
\hline 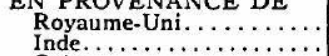 & $\begin{array}{r}856 \\
1,604\end{array}$ & 二 & $\underline{49}$ & $\begin{array}{r}905 \\
1,504\end{array}$ & $\underline{400}$ & 二 & 11 & 411 \\
\hline Cuba...................... & 253 & 一 & $\overrightarrow{0 \pi}$ & 253 & $=$ & $=$ & $\overrightarrow{A 6}$ & $\overline{\Delta G}$ \\
\hline 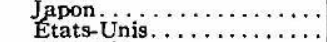 & 二 & 二 & $\begin{array}{l}27 \\
22\end{array}$ & $\begin{array}{r}27 \\
22\end{array}$ & 二 & 二 & $\begin{array}{l}46 \\
45\end{array}$ & $\begin{array}{l}46 \\
45\end{array}$ \\
\hline Australie............... & 158 & - & $\frac{2}{2}$ & 168 & 二 & $\overline{-}$ & $\frac{2}{17}$ & 17 \\
\hline $\begin{array}{l}\text { Hong-Kong } \ldots \ldots \ldots \ldots \ldots \\
\text { Italie. } \ldots, \ldots, \ldots \ldots \ldots\end{array}$ & 二 & $\overline{15}$ & - & 15 & 二 & 2 & 17 & 2 \\
\hline Allemagne Union Sud-Africaine $\ldots$ & 二 & 二 & $\overline{330}$ & 330 & 二 & $\underline{1}$ & 1 & $\underline{2}$ \\
\hline Tot & 771 & 15 & 430 & 3,216 & 400 & 8 & 120 & 523 \\
\hline
\end{tabular}




\section{L'ALUMINIUM AU CANADA}

n'est pour lui qu'un médiocre fournisseur: 1,400 tonnes en 1959, guère plus de 1,000 en 1960, car ce pays achète des articles fabriqués en Europe principalement. Il en est de même pour la plupart des autres pays des Antilles et d'Amérique latine où le Canada n'a que des exportations dérisoires. Ne pourrait-on pas faire mieux?

L'Asie nous offre toutefois de meilleurs clients que l'Amérique latine. Le volume des exportations canadiennes a augmenté du tiers dans cette direction de 1959 à 1960, passant de 45,000 à 75,000 tonnes (voir le tableau XI et les graphiques III et IV). Les courants maritimes montrent la presque totalité de ce volume, soit 40,000 tonnes en 1959 et 71,000 tonnes en 1960. Or, ces courants encerclent littéralement le globe terrestre, les clients du Canada se trouvant aux antipodes. En 1959, par exemple, les pays d'ExtrêmeOrient et du Sud-Est asiatique ont reçu environ 24,500 tonnes par les routes du Pacifique (graphique III) dont 1,800 tonnes via Panama. Les pays de l'Asie méridionale ont reçu environ 14,000 tonnes par l'Atlantique, la Méditerranée et Suez et un autre millier acheminé dans la même direction via Panama. En 1960, les courants qui ont grossi prennent la même orientation.

Voyons la place qu'occupe le Canada dans le ravitaillement de ces pays en aluminium, du moins celle de nos meilleurs clients. L'Inde, dont la principale fabrique est à Hirakud, n'en produit encore qu'environ 18,000 tonnes et en importe autant. Le Canada est d'emblée son premier fournisseur suivi de loin par le RoyaumeUni. Mais l'Inde projette de quadrupler sa capacité de production (tableau II) en construisant plusieurs usines, l'une au barrage de Rihand (Uttar Pradesh) avec Kaiser Aluminum, une autre près de Madras avec la Cie Péchiney, et une troisième à Kolhapur avec laide italienne. L'avenir des exportations canadiennes vers ce pays en sera affecté.

Le Japon n'achète guère que 20,000 à 25,000 tonnes d'aluminium à l'étranger. Il est doté d'une capacité de production croissante qui dépasse 100,000 tonnes, dont la moitié est aux mains de la Japan Light Metals Co. (usines de Kambara, Niigata et Kitagata). Le Canada, en 1959, fut son principal fournisseur, suivi par les Etats-Unis avec la moitié moins; mais en 1960, même si nos ventes ont doublé, la concurrence américaine est plus vive et le Japon exporte lui-même des articles d'aluminium. 
L'ACTUALITÉ ECONOMIQUE

Tableau XIa

Exportations canadiennes de l'aluminium brut, semi-ouvré et ouvré

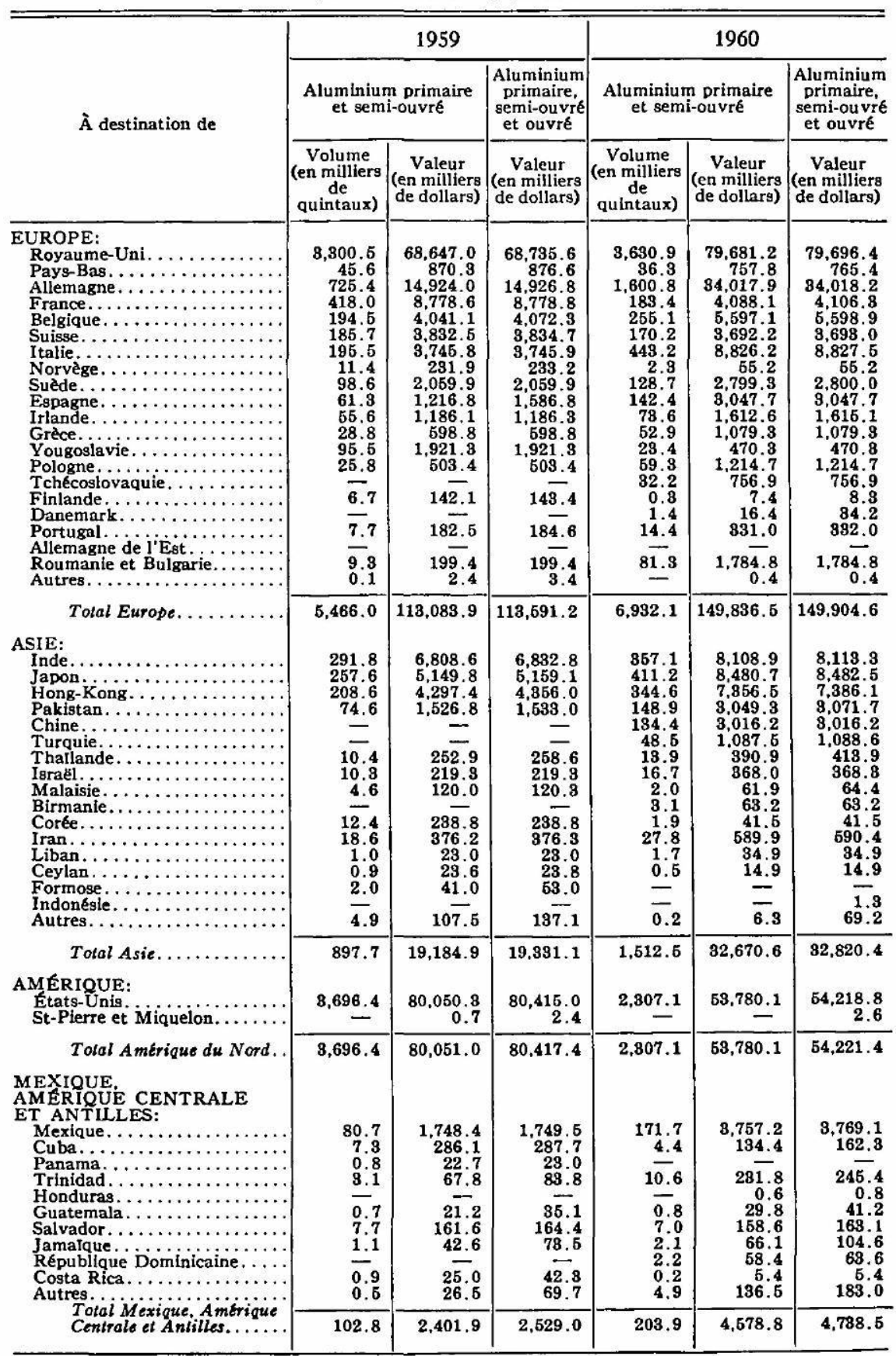




\section{L'ALUMINIUM AU CANADA}

Tableau XIa (suite)

\section{Exportations canadiennes de l'aluminium brut, semi-ouvré et ouvré}

\begin{tabular}{|c|c|c|c|c|c|c|}
\hline \multirow{3}{*}{ À destination de } & \multicolumn{3}{|c|}{1959} & \multicolumn{3}{|c|}{1960} \\
\hline & \multicolumn{2}{|c|}{$\begin{array}{l}\text { Aluminium primaire } \\
\text { et semi-ouvré }\end{array}$} & \multirow{2}{*}{$\frac{\begin{array}{c}\text { Aluminium } \\
\text { primaire, } \\
\text { semi-ouvre } \\
\text { et ouvre }\end{array}}{\begin{array}{c}\text { Valeur } \\
\text { (en milliers } \\
\text { de dollars) }\end{array}}$} & \multicolumn{2}{|c|}{$\begin{array}{l}\text { Aluminium primaire } \\
\text { et semi-ouvré }\end{array}$} & \multirow{2}{*}{$\mid \begin{array}{c}\begin{array}{c}\text { Aluminium } \\
\text { primalire, } \\
\text { semi-ouvre } \\
\text { et ouvré }\end{array} \\
\begin{array}{c}\text { Valeur } \\
\text { (en milliers } \\
\text { de dollars) }\end{array}\end{array}$} \\
\hline & $\begin{array}{c}\text { Volume } \\
\text { (en milliers } \\
\text { de } \\
\text { quintaux) }\end{array}$ & $\left|\begin{array}{c}\text { Valeur } \\
\text { (en milliers } \\
\text { de dollars) }\end{array}\right|$ & & $\begin{array}{c}\text { Volume } \\
\text { (en milliers } \\
\text { de } \\
\text { quintaux) }\end{array}$ & $\begin{array}{c}\text { Valeur } \\
\text { (en milliers } \\
\text { de dollars) }\end{array}$ & \\
\hline 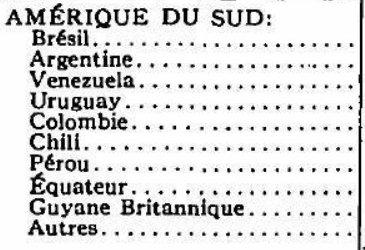 & $\begin{array}{r}121.9 \\
96.6 \\
28.5 \\
24.6 \\
14.0 \\
21.1 \\
4.9 \\
\overline{1.5}\end{array}$ & $\begin{array}{r}2,342.0 \\
1,866.1 \\
744.0 \\
479.6 \\
347.2 \\
451.1 \\
152.4 \\
\overline{7} \\
47.1 \\
\end{array}$ & $\begin{array}{r}2.401 .8 \\
1.866 .1 \\
898.5 \\
479.6 \\
464.5 \\
454.1 \\
161.2 \\
=\quad \overline{67.8} \\
\end{array}$ & $\begin{array}{r}258.5 \\
112.8 \\
21.0 \\
81.1 \\
21.4 \\
18.8 \\
10.7 \\
0.5 \\
2.9 \\
0.4\end{array}$ & $\begin{array}{r}5,370.8 \\
2,329.0 \\
594.6 \\
676.4 \\
497.0 \\
414.7 \\
283.1 \\
22.8 \\
102.7 \\
12.0 \\
\end{array}$ & $\begin{array}{r}5,396.0 \\
2,829.0 \\
678.0 \\
676.8 \\
521.1 \\
417.2 \\
288.8 \\
28.8 \\
152.2 \\
15.1 \\
\end{array}$ \\
\hline Total Amerigue du Sud... & 313.1 & $6,429.5$ & 6.793 .6 & 478.1 & $10,302.6$ & $10,503.0$ \\
\hline Total Amerique.......... & $4,112.8$ & $88,882.4$ & $89,740.0$ & $2,989.1$ & $68,651.6$ & $69,462.9$ \\
\hline 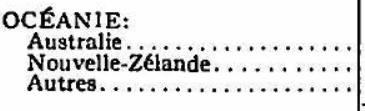 & $\begin{array}{r}829.6 \\
29.4 \\
-\end{array}$ & $\begin{array}{r}6.940 .5 \\
667.2 \\
- \\
\end{array}$ & $\begin{array}{r}6.942 .2 \\
694.8 \\
2.8 \\
\end{array}$ & 二 & 二 & 二 \\
\hline Total Ockanie............ & 359.0 & $7,607.7$ & $7,688.8$ & 565.6 & $12,590.2$ & $12,662.8$ \\
\hline 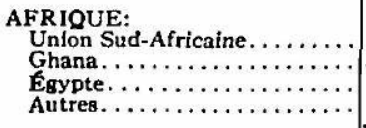 & $\frac{99.5}{\overline{1.5}}$ & $\frac{2,055.0}{\overline{77.1}}$ & $\frac{2,056.5}{67.4}$ & $\begin{array}{r}187.7 \\
7.6 \\
0.1 \\
5.6 \\
\end{array}$ & $\begin{array}{r}4.247 .3 \\
166.5 \\
8.9 \\
121.7\end{array}$ & $\begin{array}{r}4.252 .0 \\
166.6 \\
17.4 \\
132.4\end{array}$ \\
\hline & 101.0 & $2,092.1$ & $2,123.9$ & 200.9 & $4,589.4$ & $4,568.4$ \\
\hline & $10,936.0$ & $230,851.0$ & $232,425,0$ & $12,202.2$ & $268,298.8$ & $269,419.1$ \\
\hline
\end{tabular}

Hong-Kong est devenu un marché intéressant pour le Canada qui est à peu près seul à lui fournir les 12,000 ou 15,000 tonnes qu'il requiert. Et en 1960, un marché nouveau vient de s'ouvrir, celui de la Chine continentale, où le Canada a exporté environ 7,000 des 12,000 tonnes importées dans ce pays. Le Canada semble y avoir supplanté la Norvège qui avait fourni à la Chine 8,000 des 10,000 tonnes importées en 1959. Toutefois, la Chine produit déjà environ 70,000 tonnes d'aluminium et projette d'accroître ses usines existantes à Fusin, en Mandchourie, et à Siang, dans le Tchang-Si, ainsi que de multiplier ses fabriques artisanales.

Au cours de 1960, d'autres clients non négligeables sont apparus pour le Canada en Asie, comme la Turquie, l'Iran, la Thailande et Israël, où il n'existe aucune industrie primaire d'aluminium. 
En Océanie, le Canada vend à ses deux partenaires du Commonwealth des quantités croissantes d'aluminium, près de 20,000 tonnes en 1959, et près de 30,000 tonnes en 1960. Seule l'Australie possède une usine, celle de la baie Bell dont la capacité est d'une quinzaine de mille tonnes, destinée à être doublée. Ce pays importe environ 20,000 tonnes en 1959, le double en 1960. La NouvelleZélande en requiert de 5,000 à 8,000 tonnes. Le Canada est leur principal fournisseur, mais les exportations anglaises et américaines se sont fortement accrues dans cette direction en 1960.

Reste l'Afrique, où le Canada ne joue encore qu'un rôle modes. te. Il n'y a, en effet, qu'un client, l'Union Sud-Africaine, dont il est le principal fournisseur, mais non le seul, car la Norvège y vend la moitié autant d'aluminium que le Canada. On sait que les jeunes pays d'Afrique s'outillent. Péchiney a ouvert, en 1957, une usine au Cameroun, à Edea, qui produit déjà plus de 40,000 tonnes et pourrait être doublée. La même société française s'intéresse à celle de Cambambé, en Angola, qui doit débuter avec 25,000 tonnes en 1961. Mais il existe des projets encore plus grandioses. Même si l'Alcan a renoncé à 'ses installations en Guinée, d'autres y demeu. rent, comme Péchiney à Konkouré $(155,000$ t.) et Fria (consortium international) sur le même territoire (150,000 t.). Même le Mali ambitionne d'avoir des usines d'aluminium à Kouilou. Donc, d'ici quelques années, les pays d'Afrique deviendront des fournisseurs et non des clients sur le marché international de l'aluminium.

Le plus fort volume de l'aluminium exporté quitte le Canada par ses ports de mer, ainsi que nous l'avons vu précédemment. Le tableau XII montre les mouvements maritimes aux ports canadiens en 1959, année pour laquelle on connaît toutes les données du commerce extérieur et intérieur. Seul le commerce avec les pays étrangers n'est pas encore publié pour 1960, au moment où nous écrivons. Les plus gros chargements destinés aux pays étrangers se font, il est évident, aux ports du Saint-Laurent, dans le Québec, au voisinage des usines. Tel est, par exemple, Port-Alfred qui a expédié hors du Canada 151,000 tonnes, en 1959, et davantage en 1960 (181,500 t.). C'est l'exutoire d'Arvida, de l'Isle-Maligne et d'une portion de Baie-Comeau. $\mathrm{Ce}$ dernier port expédie vers 


\section{L'ALUMINIUM AU CANADA}

l'étranger 33,600 tonnes en 1959 et un peu plus en 1960 (36,300 t.). Celui de Trois-Rivières ajoute 12,200 tonnes à ce trafic en 1959 et près de 20,000 tonnes en 1960. Enfin Québec et Montréal complètent la liste avec 7,500 tonnes en 1959 et presque le double en 1960. De sorte que les ports du Saint-Laurent chargent un volume considérable, soit 205,000 tonnes en 1959 et 251,400 tonnes en 1960 . Les ports de l'Atlantique, surtout Saint-Jean (N.-B.), les seuls ouverts toute l'année, expédient, en hiver surtout, près de 12,000 tonnes en 1959 et plus de 16,000 tonnes en 1960. Viennent ensuite ceux du Pacifique, où Kitimat, on s'en doute, est le principal avec

\section{Tableau XII}

Commerce de l'aluminium par eau aux ports canadiens, en $1959^{3}$ (en tonnes faibles)

\begin{tabular}{|c|c|c|c|c|c|c|c|c|}
\hline \multirow{3}{*}{ En provenance de } & \multicolumn{3}{|c|}{$\begin{array}{l}\text { Cargaisons chargées } \\
\text { a destination de }\end{array}$} & \multirow{3}{*}{$\begin{array}{l}\text { Total } \\
(1959)\end{array}$} & \multicolumn{3}{|c|}{$\begin{array}{l}\text { Cargaisons déchargées } \\
\text { en provenance de }\end{array}$} & \multirow{3}{*}{$\begin{array}{l}\text { Total } \\
\text { (1959) }\end{array}$} \\
\hline & \multicolumn{2}{|c|}{ pays étrangers } & \multirow{2}{*}{$\begin{array}{c}\text { ports ca- } \\
\text { nadiens } \\
\text { (1959) }\end{array}$} & & \multicolumn{2}{|c|}{ pays étrangers } & \multirow{2}{*}{$\mid \begin{array}{c}\text { ports ca- } \\
\text { nadiens } \\
\text { (1959) }\end{array}$} & \\
\hline & 1959 & 1960 & & & 1959 & 1960 & & \\
\hline 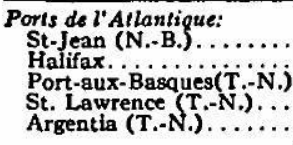 & $\begin{array}{c}7,554 \\
4,172 \\
= \\
=\end{array}$ & $\begin{array}{c}14,325 \\
2,169 \\
= \\
\end{array}$ & $\begin{array}{l}= \\
=\end{array}$ & $\begin{array}{c}7.554 \\
4,172 \\
= \\
\end{array}$ & $\begin{array}{c}1,842 \\
= \\
=\end{array}$ & $\begin{array}{l}106 \\
26 \\
= \\
=\end{array}$ & $\begin{array}{r}- \\
1 \\
52 \\
36 \\
8\end{array}$ & $\begin{array}{r}1,842 \\
1 \\
52 \\
85 \\
8\end{array}$ \\
\hline Souss-tctal. ........ & 11,726 & 16,484 & - & 11,726 & 1,842 & 182 & 91 & 1.938 \\
\hline 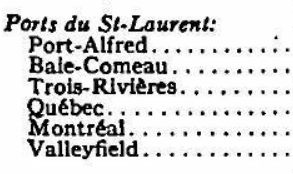 & $\begin{array}{r}150,912 \\
88,686 \\
12,199 \\
4,614 \\
2,989 \\
600 \\
\end{array}$ & $\begin{array}{c}181,499 \\
86,841 \\
19,848 \\
7,6841 \\
6,661 \\
- \\
\end{array}$ & $\begin{array}{r}7.880 \\
18,084 \\
75 \\
= \\
= \\
\end{array}$ & $\begin{array}{r}158,792 \\
51,670 \\
12,274 \\
4,614 \\
2,989 \\
600 \\
\end{array}$ & $\begin{array}{r}- \\
259 \\
18 \\
614 \\
\end{array}$ & $\begin{array}{r}- \\
6 \\
15 \\
247 \\
\end{array}$ & $\begin{array}{l}7,561 \\
6,920 \\
= \\
\end{array}$ & $\begin{array}{r}7,561 \\
7,178 \\
18 \\
614 \\
\end{array}$ \\
\hline Sous-total........ & 204,800 & 251,4288 & 26,039 & 280,889 & 929 & 400 & 14,481 & 15,410 \\
\hline 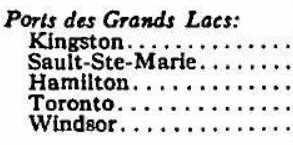 & $\begin{array}{r}\overline{171} \\
38 \\
4 \\
- \\
\end{array}$ & $\begin{array}{l}\bar{z} \\
\bar{z}\end{array}$ & $\begin{array}{l}194 \\
= \\
=\end{array}$ & $\begin{array}{r}194 \\
171 \\
88 \\
-4 \\
-\end{array}$ & $\bar{z}$ & $\begin{array}{l}= \\
-3 \\
-\end{array}$ & $\begin{array}{c}17.848 \\
= \\
9\end{array}$ & $\frac{17,848}{\frac{15}{9}}$ \\
\hline Sous-tolal. ........ & 218 & - & 194 & 407 & 15 & 3 & 17.867 & 17.871 \\
\hline 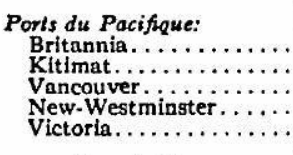 & $\begin{array}{r}122.089 \\
2.926 \\
668 \\
\end{array}$ & $\begin{array}{r}117,772 \\
8,448 \\
621 \\
- \\
\end{array}$ & $\begin{array}{c}18, \overline{472} \\
= \\
=\end{array}$ & $\begin{array}{r}135, \overline{561} \\
2,926 \\
668 \\
\end{array}$ & $\frac{\overline{7}}{\frac{408}{22}}$ & $\frac{-}{\frac{75}{45}}$ & $\underset{9 . \overrightarrow{957}}{=}$ & $\frac{\bar{z}}{14,365}$ \\
\hline Sous-total. . . . . . & 125.688 & 121,858 & 19,472 & 189,165 & 480 & 120 & 9.957 & 14,387 \\
\hline . Total............ & 842,422 & 389,770 & 89,705 & 382,127 & 8,216 & 523 & 42,386 & 45,602 \\
\hline
\end{tabular}

1. $\mathrm{Y}$ compris Lévis.

2. Ports de l'Atlantique et du Saint-Laurent.

3. Les données de 1960 pour les ports canadiens ne sont pas encore publikes. 
122,100 tonnes en 1959, et un peu moins l'année suivante. Il en passe aussi de 3,000 à 4,000 tonnes par Vancouver.

Outre le commerce maritime d'outre-mer, il existe une circulation par eau de l'aluminium à l'intérieur du Canada. On en connaît les courants commerciaux pour 1959, de façon assez approximative, puisque les chargements au cabotage dépassent de 2,681 tonnes les déchargements. Nous avons pu quand même les suivre grosso modo. Les ports du Saint-Laurent expédient 26,000 tonnes, dont 18,000 de Baie-Comeau et près de 8,000 de Port-Alfred. La moitié de ce total est livrée dans le Québec, soit 7,600 tonnes à Port-Alfred (aluminium venant de Baie-Comeau, sans doute) et près de 7,000 à Trois-Rivières, ce qui explique les expéditions de 12,200 tonnes de ce port vers l'étranger, le reste venant sans doute de Shawinigan. Où va le reste du tonnage chargé au cabotage? $\bar{A}$ Kingston en majorité, car là se trouve l'usine ontarienne principale de fabrication. Kingston reçoit, en effet, près de 18,000 tonnes en provenance de ports canadiens. Sur le littoral du Pacifique, Kitimat expédie 13,500 tonnes au cabotage, dont près de 10,000 à Vancouver. Mais que devient le reste? Il est vraisemblable qu'un volume de 3,500 tonnes soit à destination des ports orientaux du Canada via le canal de Panama.

Les statistiques ferroviaires des produits usinés de l'aluminium apparaissent sous deux rubriques: l'aluminium brut (code no 555) et les autres articles (code no 557). Le trafic du premier (tableaux IX et X) est d'environ 350,000 tonnes en 1959, et 391,000 tonnes en 1960; celui du second groupe est moindre, soit une soixantaine dè mille tonnes par année.

Les chargements de l'aluminium brut se font, il va sans dire, aux lieux de la production: près de 300,000 tonnes en 1959 dans le Québec (350,000 t. en 1960) et environ 38,000 tonnes en ColombieBritannique (28,000 tonnes en 1960). Lorsqu'il s'agit, comme dans le cas actuel, d'un produit usiné dont la valeur est élevée (465 dollars la tonne faible), les mouvements sont plus complexes que ceux d'une matière première, telle que la bauxite ou l'alumine. Examinons d'abord les quantités chargées aux gares dans les provinces. Pour le Québec, on reconnaît facilement où les quelque 300,000 tonnes furent chargées en 1959 (près de 350,000 tonnes en 
1960). Le chemin de fer Roberval \& Saguenay en prend 103,400 tonnes (127,500 tonnes en 1960) à Arvida; l'Alma \& Jonquière, 64,300 tonnes $(78,800 \mathrm{t}$. en 1960) à l'Isle-Maligne. Le Pacifique Canadien en charge 13,800 tonnes (24,300 t. en 1960) vraisemblablement à Shawinigan, et le St. Lawrence \& Adirondack, 9,300 tonnes (10,400 t. en 1960) probablement à Beauharnois ou à Valleyfield. Par élimination, on arrive à connaître les chargements dans le Québec du National Canadien en enlevant de son total les chargements effectués en Colombie-Britannique et en Ontario. Il reste 104,900 tonnes en 1959, 105,300 tonnes en 1960, volume qu'il a pris surtout à Arvida et un peu à Shawinigan. Où les livraisons se font-elles? D'abord à Port-Alfred, où le Roberval \&? Saguenay laissent 147,000 tonnes en 1959 , et 176,600 tonnes en 1960 , donc plus qu'il n'a chargé. On connaît les livraisons du Québec aux États-Unis: 29,100 tonnes en 1959, 17,600 tonnes en 1960, ainsi que celles qui ont été faites aux provinces maritimes: 43,300 tonnes en 1959, 71,000 en 1960. Par voie de soustraction, on connaît, en outre, les livraisons locales faites dans le Québec: 9,100 tonnes en 1959 et 32,300 en 1960 . Le reste, soit 70,000 tonnes en 1959 et 54,000 en 1960, ne peut être acheminé ailleurs qu'en Ontario (tableau XIII). Il se fait donc un trafic important d'aluminium brut par voie ferrée au Québec, dont la moitié toutefois sur une courte distance, entre les usines d'Arvida et l'Isle-Maligne vers Port-Alfred, mais le reste se fait sur l'ensemble du réseau vers les ports de Saint-Jean (N.-B.) et d'Halifax, vers les points de raccordements aux voies américaines et vers l'Ontario.

Hors du Québec, c'est en Colombie-Britannique, à Kitimat évidemment, que se font les plus gros chargements sur rail: 38,000 tonnes en 1959, 28,000 en '1960. La majeure partie s'oriente vers l'Est, vers l'Ontario vraisemblablement, traversant les Rocheuses et la Prairie: 36,500 tonnes en 1959, 20,100 en 1960. Exprimé en tonnes-mille, ce serait sans doute un des plus puissants courants de marchandises au Canada. Il faut qu'il en soit ainsi, car l'Ontario, privée d'usines d'électrolyse, n'a que de minimes chargements locaux: 4,800 tonnes en 1959, encore moins en 1960, et n'en reçoit guère davantage des voies américaines. Pourtant ses livraisons sont considérables: 113,800 tonnes en 1959, 82,300 en 1960. L'Ontario en livre une part à ses propres industries de transformation 


\section{L'ACTUALITE ECONOMIQUE}

(Kingston et Toronto), soit environ 25,000 tonnes par an, mais la majeure partie file vers les Etats-Unis: 88,500 tonnes en 1959 et près de 59,000 en 1960. Bref, on constate que l'aluminium canadien est un fret de choix puisqu'il circule d'un océan à l'autre.

Les autres articles manufacturés en aluminium fournissent un fret plus modeste, dont les mouvements sont décalqués sur les précédents à une exception près. Le Québec dispose de plus forts chargements: 44,800 tonnes et davantage en 1959, 60,900 en 1960, grâce aux usines d'Arvida, de Trois-Rivières, de Shawinigan et de Beauharnois qui fabriquent des fils, des pièces moulées, et une foule d'autres articles. Plus de la moitié reste cependant dans la Province,

\section{Tableau XIII}

\section{Mouvement ferroviaire apparent de l'aluminium brut, en 1959 et 1960}

(Volume transporté par rail entre les provinces canadiennes et en direction des Etats-Unis)

(en milliers de tonnes faibles)

\begin{tabular}{|c|c|c|c|c|c|c|}
\hline \multirow{2}{*}{ Provinces } & \multirow{2}{*}{$\begin{array}{l}\text { Excedent des } \\
\text { livraisons } \\
\text { gur les } \\
\text { chargements }\end{array}$} & \multirow{2}{*}{$\begin{array}{c}\text { Excédent } \\
\text { dirlgé } \\
\text { vera }\end{array}$} & \multirow{2}{*}{$\begin{array}{l}\text { Deficit des } \\
\text { Ilvraisons } \\
\text { sur les } \\
\text { chargements }\end{array}$} & \multirow{2}{*}{$\begin{array}{l}\text { Deficit } \\
\text { comblé par } \\
\text { livraisons } \\
\text { de }\end{array}$} & \multicolumn{2}{|c|}{ Livraisons } \\
\hline & & & & & Etats-Unisls & $\begin{array}{c}\text { totales hors } \\
\text { de la } \\
\text { Province }\end{array}$ \\
\hline $\begin{array}{l}1959 \\
\text { Nouveau.Brunswick et } \\
\text { Nouvelle-Ecosse........ }\end{array}$ & & & 43.3 & Québec & & \\
\hline Québec............... & $\left\{\begin{array}{l}43.3 \\
70.0\end{array}\right.$ & $\begin{array}{l}\text { Nouveaus } \\
\text { Brunswick } \\
\text { et N.E. } \\
\text { Ontario }\end{array}$ & & ..... & 29.1 & 142.4 \\
\hline Ontario............... & & $\begin{array}{l}\text { Untario } \\
\text {............ }\end{array}$ & $\left\{\begin{array}{l}63.8 \\
36.5\end{array}\right.$ & Québec & 88.5 & $88.6^{1}$ \\
\hline Colombie-Britannique. . & 36.5 & Ontario & & & 0.9 & 37.4 \\
\hline $\begin{array}{l}1960 \\
\text { Nouveau-Brunswick et } \\
\text { Nouvelle-Bcosse........ }\end{array}$ & & & 71.0 & Québec & & \\
\hline Québec....... & $\left\{\begin{array}{l}71.0 \\
\end{array}\right.$ & $\begin{array}{l}\text { Nouveau } \\
\text { Brunswick } \\
\text { et } \text { N.E. } \\
\text { Ontario }\end{array}$ & ... & $\cdots \cdots \cdots$ & 17.6 & 142.5 \\
\hline Ontario.......... & (1) & & $\left\{\begin{array}{l}52.1 \\
20.1\end{array}\right.$ & $\begin{array}{l}\text { Quebec } \\
\text { Col.-Brit. }\end{array}$ & 58.9 & $60.1^{3}$ \\
\hline Colombie-Britannique.. & 20.1 & Ontario & & & $7.7^{\circ}$ & 27.8 \\
\hline
\end{tabular}

1. Dont 0.1 vers le Manitoba.

2. Dont 1.2 vers le Manitoba.

3. Dont 0.4 par l'Alberta. 
les livraisons locales étant de 23,600 tonniés en 1959 et 39,500 en 1960. Les excédents (tableau XIV) s'orientent vers les provinces maritimes (5,600 t. en 1959 et 8,300 t. en 1960), vers les Etats-Unis $(4,900$ t. et 4,200 t.) et surtout vèrs l'Ontario (10,700 t. en 1959 et 8,900 t. en 1960). Cette dernière ne charge que 12,000 ou 13,000 tonnes, dont peu de ses propres usines, car elle en reçoit plus de la moitié des Etats-Unis; mais l'Ontario en livre deux fois plus, soit 24,000 tonnes en 1959 et autant en 1960. Le principal courant s'oriente vers les Etats-Unis, avec une quinzaine de mille tonnes, fait par transit sur les voies américaines de la péninsule: Southern Canada (Michigan Central), Cheasapeake et Wabash. Le reste des livraisons se partage également entre celles qui sont faites dans la Province et les expéditions vers l'Ouest, aux provinces de la Prairie. C'est en ceci que le mouvement de ces marchandises diffère de

\section{Tableau XIV}

\section{Mouvement ferroviaire apparent des autres articles manufactures en aluminium, en 1959 et 1960}

(Volume transporté par rail entre les provinces canadiennes et en direction des Etats-Unis)

(en milliers de tonnes faibles)

\begin{tabular}{|c|c|c|c|c|c|c|}
\hline \multirow[b]{2}{*}{ Provinces } & \multirow{2}{*}{$\begin{array}{l}\text { Excedent des } \\
\text { livralsons } \\
\text { 8ur leg } \\
\text { chargements }\end{array}$} & \multirow{2}{*}{$\begin{array}{c}\text { Exctdent } \\
\text { diriget } \\
\text { vero }\end{array}$} & \multirow{2}{*}{$\begin{array}{l}\text { Deficit des } \\
\text { livratsons } \\
\text { our les } \\
\text { chargements }\end{array}$} & \multirow{2}{*}{$\begin{array}{c}\text { Deficit } \\
\text { comble par } \\
\text { livraisons } \\
\text { de }\end{array}$} & \multicolumn{2}{|c|}{ Livraisons } \\
\hline & & & & & Etats-Unis & $\begin{array}{l}\text { totales hors } \\
\text { de La } \\
\text { Province }\end{array}$ \\
\hline $\begin{array}{l}1959 \\
\text { Quatre provinces de I'Eot }\end{array}$ & & & 5.6 & Québec & & \\
\hline Québec............... & & $\begin{array}{l}4 \text { provinces } \\
\text { de l'Eat }\end{array}$ & & & 4.9 & 21.2 \\
\hline $\begin{array}{l}\text { Ontario............. } \\
\text { Qutatre provinces de } \\
\text { l'Ouest.......... }\end{array}$ & 10.7 & Untanio & $\begin{array}{r}10.7 \\
4.4\end{array}$ & $\begin{array}{l}\text { Québec } \\
\text { Ontario }\end{array}$ & $\begin{array}{r}15.0 \\
1.4\end{array}$ & $\begin{array}{r}19.4 \\
1.4\end{array}$ \\
\hline $\begin{array}{l}1960 \\
\text { Quatre provinces del'Est }\end{array}$ & & & 8.3 & Québec & & \\
\hline Quebec.............. & $\left\{\begin{array}{l}8.3 \\
8.9\end{array}\right.$ & $\begin{array}{l}4 \text { provinces } \\
\text { de l'Est } \\
\text { Ontario }\end{array}$ & . & $\ldots \ldots \ldots$ & 4.2 & 21.4 \\
\hline Ontario. & & & 8.9 & Québec & 14.4 & 19.2 \\
\hline $\begin{array}{l}\text { Quatre provinces de } \\
\text { l'Ouest............ }\end{array}$ & & . & $\begin{array}{l}3.2 \\
5.2\end{array}$ & $\begin{array}{l}\text { Origine } \\
\text { inconnue } \\
\text { Ontario }\end{array}$ & $\cdots_{1.3} \cdots$ & 1.3 \\
\hline
\end{tabular}


l'aluminium brut: il se fait en sens contraire, mais n'a guère d'importance.

Quel rôle le camionnage joue-til dans le transport de l'aluminium? Impossible de le savoir, car les données ne sont pas publiées. Pour l'estimer sérieusement, il faudrait connaître la production exacte de chaque usine et l'importance des stocks non livrés. Sachant quel volume s'achemine par eau et par rail, on obtiendrait celui que prennent les entreprises de camionnage. Or, il en existe sûrement, car la Canadian British Aluminium de Baie-Comeau a créé son propre service de camionnage dès 1958. Cas de force majeure, puisqu'en hiver, durant que la navigation est interrompue, la route est le seul lien possible avec sa clientèle. Il est bien certain qu'un fret de cette nature entre pour une large part dans les services réguliers qu'entretiennent les camionneurs entre Montréal et New-York, et sur les routes ontariennes vers les villes industrielles de l'Est central américain. L'Alcan à elle seule estime qu'un volume de 175,000 tonnes, comprenant l'aluminium de première fusion et les produits semi-ouvrés, a été expédié, en 1960, par camion vers les ports canadiens et vers sa clientèle du Canada et des Etats-Unis.

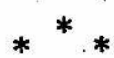

L'analyse des courants commerciaux nous a révélé l'ordre de grandeur de la production régionale de l'aluminium au Canada. Les seules données publiées sont la production totale du Canada qui fut de 593,630 tonnes (chiffre revisé) en 1959 et de 745,000 en 1960, et la production de l'Alcan, indiquée dans son rapport annuel, soit 503,500 tonnes en 1959 et 637,800 en 1960 (tableau XV). La différence, qui est de 90,130 et 107,200 tonnes, doit donc être la production des deux autres fabricants d'aluminium brut: Canadian British Aluminium de Baie-Comeau, et Chryslum Ltd de Beauharnois; ce qui correspond sensiblement à la capacité annuelle de leurs usines d'électrolyse (tableau I). Ces usines canadiennes n'ont produit qu'aux deux tiers de leur capacité en 1959, mais à 85 p.c. en 1960. La production de l'Alcan correspond assez exactement à ces pourcentages. On peut donc l'estimer en la partageant ainsi: dans le Québec, Arvida aurait fourni 250,000 tonnes en 1959. 


\section{L'ALUMINIUM AU CANADA}

et 320,000 en 1960; l'Isle-Maligne, 80,000 et 100,000 tonnes; Shawinigan, 47,500 et 60,000 tonnes; Kitimat, 126,000 et 157,800 tonnes. L'usine de Baie-Comeau produira alors 63,130 et 74,200 tonnes, celle de Beauharnois, 27,000 et 33,000 tonnes.

Si nos calculs sont exacts, le Québec aurait pu mettre environ 468,000 tonnes sur le marché en 1959, 588,000 en 1960. Les ports du Québec ont expédié, en 1959, hors de la Province, 215,319 tonnes par eau, 142,400 tonnes par rail, et la Province en a gardé 9,100 tonnes livrées par rail aux usagers locaux. Ceci constitue un mouvement global de 366,819 tonnes, inférieur aux expéditions réelles, car les navires chargent une quantité inconnue de cette marchandise parmi leurs "cargaisons générales». On aboutit toutefois à un important déficit de l'ordre de 100,000 tonnes en regard de la production estimée. Il est invraisemblable que les stocks aux usines soient aussi importants. C'est le transport par camion qui véhicule la majeure partie de ces 100,000 tonnes, moins évidemment le volume transformé sur place, comme à Arvida, où l'usine

\section{Tableau XV}

\section{La production de l'aluminium brut au Canada}

(en tonnes faibles)

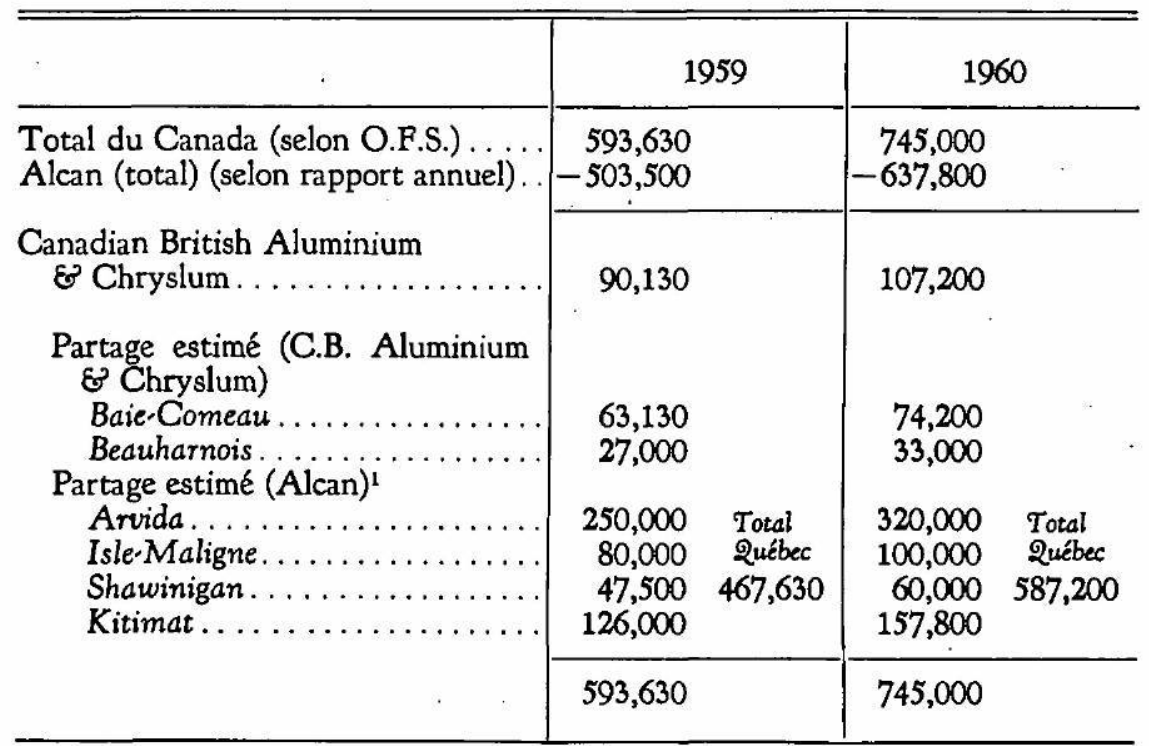

1. Les usines de l'Alcan ont produit à 66 et à 85 p.c. de leur capacité en 1959 et 1960 respectio vement. 
de produits 'finis a une capacité de 16,000 tonnes', et à Shawinigan $(28,000$ t.).

En Colombie-Britannique, il semble qu'en 1959 le volume acheminé sur les marchés ait été supérieur à celui de la production, soit plus de 170,000 tonnes contre notre estimé de 126,000 tonnes à la production. Rien d'étonnant à cela, car l'usine de Kitimat marcha au ralenti, mais les stocks accumulés antérieurement ont pu répondre aux besoins de la clientèle.

Au cours de 1959 et 1960, nous avons observé de sensibles modifications dans le commerce extérieur de l'aluminium canadien: les ventes aux Etats-Unis ont diminué d'une façon presque alarmante, celles aux pays européens ont, au contraire, assez fortement augmenté. Est-ce une nouvelle tendance, susceptible de se développer? Les résultats des neuf premiers mois de 1961, publiés par l'Alcan, montrent qu'une telle orientation n'aura été qu'éphémère, car les ventes de cette entreprise ont baissé en Europe durant cette période, et se sont accrues par contre vers le marché traditionnel des Etats-Unis.

\author{
Benoît BROUILLETTE, \\ professeur à l'Ecole des Hautes Etudes \\ commerciales (Montréal).
}

\section{a) Ouvrages gentraux: \\ Davis, John}

Goodwin, William

Revue de l'Aluminium

Minerals Year Book

Mineral Facts and Problems

The Financial Post Survey of Industrials

\section{Bibliographie sommaire}

L'extraction et le traitement des minéraux au Canada, Commission royale d'enquête sur les perspectives économiques du Canada (Commission Gordon), Imprimeur de la Reine, 1957. (chapitre V, cf. pp. 157-187).

¿Outlook for aluminum, Focus (New.York), Vol. XI, no 5, janvier 1961 ,
6 pages. (Paris), 1958 à 1961.

1958,Vol. I: Bauxite, pp. 209.227, Aluminum, pp. 147-170. 1959,Vol. I: Bauxite, pp. 223-240, Aluminum, pp. 155-182. U.S. Dept. of the Interior. Bureau of Mines, Washington, 1959 et 1960.

Édition 1960. Bulletin 585. Bureau of Mines, U.S. Dept. of the Interior, Washington, 1960. * Alumina and baurite*, pp. 15-26; * Aluminums, pp. 27.41 .

1961, 35 annibe. Maclean-Hunter Publishing Co. Ltd., Toronto, 1961. 


\section{L'ALUMINIUM AU CANADA}

Aluminium Limited Trente-troisième rapport annuel pour l'annee 1960. Montreal, 1960, 32 pages.

Memorandum of New York (N.Y.), in support of maximum possible reduction in existing Aluminium Sales Inc. tariff duty. New.York, déc. 1960, 27 pages.

b) Sources statistiques:

Ministère des Mines et

Relevés techniques Aluminium,1959, par W.H. Jackson. Rapport 2. Ottawa, 1960, 10 pages.

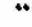

4

Office fédéral de

la Statistique

*

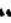

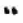

16

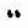

“

Nations Unies

United Nations

*.
Spath Fluor, 1959, par C.-M. Bartley. Rapport 51. Ottawa, 1960, 9 pages.

Metallurgical works in Canada, non.ferrous and precious metals, operators list, 1959 et 1960 . Ottawa, 1960 et 1961.

A preliminary review of the Canadian mineral industry in 1960, a Alumi. num and Magnesium», pp. 30-31. Ottawa, 1961.

Shipping Report, 1959, partie I, II et III. Ottawa, 1960 et 1961.

Shipping Report, 1960, partie I et II. Ottawa, 1961.

Railway freight traffic, 1959 et 1960. Ottawa, 1960 et 1961.

Railway transport, 1959, partie V, et 1960, partie V. Ottawa, 1960 et 1961.

Commerce du Canada, 1958, Vol. I, II et III. Ottawa, 1960 et 1961.

Articles exported to each country (trimestriel), sept.déc. 1959 et sept. déc. 1960. Ottawa, 1960 et 1961.

Articles imported from each country' (trimestriel), sept.dec. 1959 et sept. déc. 1960 . Ottawa, 1960 et 1961.

Annuaire statistique, 1960. New.York, 1961. Tableau 114, p. 251.

Bulletin mensuel de statistique, octobre 1961.

Commodity trade statistics, jan.dé. 1959. New.York, 1960.

Commodity trade statistics, Part I, Imports, jan.-sept. 1960; Part II. Exports, jan.sept. 1960. New.York, 1961. 